\title{
CALIPER Retail Lamps Study 3
}

Prepared for:

Solid-State Lighting Program

Building Technologies Office

Office of Energy Efficiency and Renewable Energy

U.S. Department of Energy

\section{Prepared by:}

Pacific Northwest National Laboratory 
PNNL-23132

\title{
DISCLAIMER
}

This report was prepared as an account of work sponsored by an agency of the United States Government. Neither the United States Government nor any agency thereof, nor Battelle Memorial Institute, nor any of their employees, makes any warranty, express or implied, or assumes any legal liability or responsibility for the accuracy, completeness, or usefulness of any information, apparatus, product, or process disclosed, or represents that its use would not infringe privately owned rights. Reference herein to any specific commercial product, process, or service by trade name, trademark, manufacturer, or otherwise does not necessarily constitute or imply its endorsement, recommendation, or favoring by the United States Government or any agency thereof, or Battelle Memorial Institute. The views and opinions of authors expressed herein do not necessarily state or reflect those of the United States Government or any agency thereof.

\author{
PACIFIC NORTHWEST NATIONAL LABORATORY \\ operated by \\ BATTELLE \\ for the \\ UNITED STATES DEPARTMENT OF ENERGY \\ under Contract DE-AC05-76RL01830
}

Printed in the United States of America

Available to DOE and DOE contractors from the

Office of Scientific and Technical Information,

P.O. Box 62, Oak Ridge, TN 37831-0062;

ph: (865) 576-8401

fax: $(865) 576-5728$

email: reports@adonis.osti.gov

Available to the public from the National Technical Information Service

5301 Shawnee Rd., Alexandria, VA 22312 ph: (800) 553-NTIS (6847)

email: orders@ntis.gov $<$ http://www.ntis.gov/about/form.aspx>

Online ordering: http://www.ntis.gov

This document was printed on recycled paper. 


\section{Preface}

The U.S. Department of Energy (DOE) CALiPER program has been purchasing and testing general illumination solid-state lighting (SSL) products since 2006. CALiPER relies on standardized photometric testing (following the Illuminating Engineering Society of North America [IES] approved method LM-79-08 ${ }^{1}$ ) conducted by accredited, independent laboratories. ${ }^{2}$ Results from CALiPER testing are available to the public via detailed reports for each product or through summary reports, which assemble data from several product tests and provide comparative analyses. $^{3}$

It is not possible for CALiPER to test every SSL product on the market, especially given the rapidly growing variety of products and changing performance characteristics. Starting in 2012, each CALiPER summary report focuses on a single product type or application. Products are selected with the intent of capturing the current state of the market, representing a broad range of performance characteristics. However, the selection does not represent a statistical sample of all available products.

This is a special report on LED lamps available through the retail marketplace and targeted toward general consumers. It follows similar reports published in 2011 and 2012 (products purchased in 2010 and 2011), and is intended as a continuation that identifies long-terms trends. For this report, products were selected to investigate specific hypotheses, rather than represent a sample of the increasingly large retail LED market. Therefore, comparing values for some metrics (e.g., lumen output) to past data should be done cautiously.

To provide further context, CALiPER test results may be compared to data from LED Lighting Facts, ${ }^{4}$ ENERGY $\mathrm{STAR}^{\circledR}$ performance criteria, ${ }^{5}$ technical requirements for the DesignLights Consortium ${ }^{\circledR}$ (DLC) Qualified Products List (QPL), ${ }^{6}$ or other established benchmarks. CALiPER also tries to purchase conventional (i.e., non-SSL) products for comparison, but because the primary focus is SSL, the program can only test a limited number.

It is important for buyers and specifiers to reduce risk by learning how to compare products and by considering every potential SSL purchase carefully. CALiPER test results are a valuable resource, providing photometric data for anonymously purchased products as well as objective analysis and comparative insights. However, photometric testing alone is not enough to fully characterize a product-quality, reliability, controllability, physical attributes, warranty, compatibility, and many other facets should also be considered carefully. In the end, the best product is the one that best meets the needs of the specific application.

For more information on the DOE SSL program, please visit http://www.ssl.energy.gov.

\footnotetext{
${ }^{1}$ IES LM-79-08, Approved Method for the Electrical and Photometric Measurements of Solid-State Lighting Products, covers LED-based SSL products with control electronics and heat sinks incorporated. For more information, visit http://www.iesna.org/.

${ }^{2}$ CALiPER only uses independent testing laboratories with LM-79-08 accreditation that includes proficiency testing, such as that available through the National Voluntary Laboratory Accreditation Program (NVLAP).

${ }^{3}$ CALiPER summary reports are available at http://www.ssl.energy.gov/reports.html. Detailed test reports for individual products can be obtained from http://www.ssl.energy.gov/search.html.

${ }^{4}$ LED Lighting Facts ${ }^{\circledR}$ is a program of the U.S. Department of Energy that showcases LED products for general illumination from manufacturers who commit to testing products and reporting performance results according to industry standards. The DOE LED Lighting Facts program is separate from the Lighting Facts label required by the Federal Trade Commission (FTC). For more information, see http://www.lightingfacts.com.

${ }^{5}$ ENERGY STAR is a federal program promoting energy efficiency. For more information, visit http://www.energystar.gov.

${ }^{6}$ The DesignLights Consortium Qualified Products List is used by member utilities and energy-efficiency programs to screen SSL products for rebate program eligibility. For more information, visit http://www.designlights.org/.
} 


\section{Report Summary}

The CALiPER program first began investigating LED lamps sold at retail stores in 2010, purchasing 33 products from eight retailers and covering six product categories. The findings revealed a fragmented marketplace, with large disparities in performance of different products, accuracy of manufacturer claims, and offerings from different retail outlets. Although there were some good products, many were not viable competitors to other available options, with too little lumen output, unacceptably low efficacy, or poor color quality. CALiPER took another look in late 2011-purchasing 38 products from five different categories and nine retailers-and the improvement was marked. Performance was up; retailer claims were more accurate; and the price per lumen and price per unit efficacy were down, although the price per product had not changed much. Nonetheless, there was still plenty of room for improvement, with the performance of LED lamps not yet reaching that of well-established classes of conventional lamps (e.g., $75 \mathrm{~W}$ incandescent A19 lamps).

Since the second retail lamp study was published in early 2012, there has been substantial progress in all aspects of LED lamps available from retailers. To document this progress, CALiPER again purchased a sample of lamps from retail stores -46 products in total, focusing on A19, PAR30, and MR16 lamps. Instead of a random sample, however, the products were chosen to answer specific hypotheses about performance. These hypotheses focused on expanding ranges of LED equivalency, the accuracy of lifetime claims, efficacy and price trends, as well as changes to product designs. Among other results, key findings include:

- There are now very good LED options to compete with $60 \mathrm{~W}, 75 \mathrm{~W}$, and $100 \mathrm{~W}$ incandescent A19 lamps, and $75 \mathrm{~W}$ halogen PAR30 lamps.

- MR16 lamps have shown less progress, but there are now acceptable alternatives to $35 \mathrm{~W}, 12 \mathrm{~V}$ halogen MR16 lamps and $50 \mathrm{~W}, 120 \mathrm{~V}$ halogen MR16 lamps for some applications. Other uses, such as in enclosed luminaires, may require more development.

- At the same price point, lamps purchased in 2013 tended to have higher output and slightly higher efficacy than in 2011 or 2010.

- More than $30 \%$ of the products purchased in 2013 exceeded the maximum efficacy measured in 2011 $(71 \mathrm{~lm} / \mathrm{W})$, with the most efficacious product measured at $105 \mathrm{Im} / \mathrm{W}$.

- There appears to be increasing consistency in color quality, with a vast majority of products having a CCT of $2700 \mathrm{~K}$ or $3000 \mathrm{~K}$ and a CRI between 80 and 85 . There were also fewer poor-performing products tested and more high-performing products available in 2013 than in previous years.

- The accuracy of equivalency and performance claims was better than in 2011, but remains a concern, with $43 \%$ of tested products failing to completely meet their equivalency claim and $20 \%$ of products failing to match the manufacturer's performance data.

Although progress has been substantial, on average LED lamps remain more expensive than other energyefficient lighting technologies-but can be superior in some aspects. While not universal to all product lines or all product types, the issue of insufficient lumen output from LED lamps is waning. Thus, manufacturers can focus on other issues, such as reducing cost, improving electrical/dimmer compatibility, eliminating flicker, or improving color quality. While these issues are not inherent to all products, they remain a concern for the broader market.

\section{Subsequent Reports}

As has become customary for CALiPER-tested products, a subset of the lamps tested for this report is undergoing additional investigation-including a subset being operated in a long-term test apparatus, for example. Additional reports will be published as data becomes available. 


\section{Background}

Although the potential energy savings may be lower for residential applications than commercial applications, market wide adoption of energy-efficient LED technology will depend in part on consumer acceptance. While many consumers are now familiar with LED technology, there is an increasingly complex market with a rapidly growing number of options. What once was a handful of options on store shelves is now dozens or hundredsor maybe even thousands online-and each option has many different performance attributes. While characteristics like lumen output may be starting to exhibit relatively standardized levels (e.g., 450 and $800 \mathrm{~lm}$ for A lamps), luminous intensity distribution, electronic compatibility, and dimmability may vary more substantially between products a consumer might view as interchangeable-and these are just a few examples.

A variety of high-quality LED lamps that cover a majority of the product types familiar to consumers are available, but lower quality products making inaccurate claims also persist. Notably, competition for market share and development of the technology has led to more widespread availability of LED products at lower price points, but that also results in a lack of correlation between price and performance; when buying a more expensive bulb does not equate to buying performance, consumers must be more knowledgeable about performance metrics, the range of available performance, and the needs of their application. In the past, "light bulbs" have been a commodity item, but with the extended lifetime of LED products and the capability improvements associated with moving from an "analog" to "digital" device, optimized solutions will depend to some degree on changing consumer attitudes and increasing knowledge of lighting systems. Even if the number of manufacturers eventually reduces to the same order of magnitude as seen with conventional lighting, the diversity of products is unlikely to ever be reduced to what it was just 10 years ago.

While consumer education remains a challenge, access to quality products has shown substantial improvement since CALiPER's previous investigations of lamps sold through retail channels. In 2013, many available A lamps matched the lumen output of a $60 \mathrm{~W}$ incandescent lamp, and some were even comparable to $75 \mathrm{~W}$ or $100 \mathrm{~W}$ lamps, with a similar story across most-if not all-product categories. Further, there were many options having a luminous intensity distribution similar to conventional incandescent lamps, with color quality suitable for most applications. The past two years also provided more variety in directional lamps, with higher output and improved efficacy. While LED lamps may still cost more than incandescent lamps-or other energy-efficient alternatives - the margin is becoming much smaller and in some cases it is possible to justify a purchase based on performance advantages alone, apart from life-cycle costs.

\section{Program History and Goals}

By 2010, many SSL stakeholders were concerned that the increasing availability of poorly performing LED lamps in retail stores could result in widespread buyer dissatisfaction with SSL technology-despite its acknowledged potential. Although CALiPER had tested many high-performance products, the large disparity among retail products was troubling because buyers in the retail market are typically not as discerning as lighting designers and other specifiers. Beginning in July 2010, a special effort was initiated to identify and test LED lamps available to the public through retail stores and websites. A total of 33 products were selected-covering A, PAR20, PAR30, MR16, B10, and C7 shapes-which were bought from eight different retailers. In April 2011, DOE published its first report on retail lamps (RRL1), ${ }^{7}$ making the following observations:

- The disparity between high-performing and low-performing products was striking.

\footnotetext{
${ }^{7}$ For more information, see Special Summary Report: Retail Replacement Lamp Testing, available at http://www1.eere.energy.gov/buildings/ssl/reports.html.
} 
- While there were some high-performing LED lamps available through retail channels, most of the products tested failed to meet basic performance levels of the incandescent, halogen, or CFL lamps they intended to replace.

- To be able to determine whether or not an LED lamp would meet performance expectations, consumers would have to be highly informed about lamp performance characteristics and would have to develop mechanisms to recognize and understand factual information from product labeling.

- There were substantial differences among manufacturers; some made LED lamps that consistently met expectations, but others were very inconsistent.

- There were substantial differences among retailers; some appeared to screen the LED lamps they carried, with most of the products performing well and having suitable labeling, whereas others did not.

With these results as a foundation, a second retail lamp study (RRL2) commenced with product purchasing in November 2011. The goal was to capture a new snapshot of the market and evaluate performance changes with respect to retailers, manufacturers, and product types. The overall scope was similar to the previous retail lamp study; in selecting products, the intent was to capture a representative sample of the different general illumination LED products currently available-including omnidirectional, directional, and decorative lampsfrom a variety of popular retail outlets. In total, 38 products were tested, including 11 A19 lamps, 5 G25 lamps, 9 120 V MR16/PAR16 lamps, 5 PAR20/R20 lamps, and 8 PAR30/R30 lamps. Specifically, in comparison to the first retail lamp study:

- There continued to be a range in performance, but fewer products were considered unacceptable in terms of lumen output, efficacy, and color quality.

- A much higher percentage of products were comparable (or superior) to the incandescent and CFL lamps they were intended to replace-at least in terms of attributes that can be directly compared.

- Many more products included a Lighting Facts label-either LED Lighting Facts or FTC Lighting Facts-or were ENERGY STAR qualified, which is likely to foster more effective consumer evaluations.

- A much higher percentage of products were measured within tolerance of listed performance values, so there were fewer obvious disparities among different manufacturers and different retailers.

- Perhaps most notably, the price per kilolumen decreased from $\$ 138.62$ to $\$ 62.25$ in just over one year, and the price per lumen-per-watt also decreased substantially.

These results were generally favorable, but it was clear that the maturation of LED lamps was still ongoing. The CALiPER program did not pursue a retail lamp study in 2012, but by mid-2013, almost complete product turnover has resulted in a dramatically different landscape. With increased numbers of available products, however, selecting an appropriate random sample was determined to be less valuable; even looking at just the five product types previously examined, there were hundreds of unique products available. Thus, the 46 LED products that were purchased for this study were chosen based on deficiencies identified in the previous two retail lamp studies and were used to test several specific hypotheses.

\section{Product Selection}

Unlike most prior CALiPER investigations, including RRL1 and RRL2, this study was conceived around answering specific questions. Several of the hypotheses are outlined here, along with a description of which products were analyzed to provide an answer, if applicable. Additional hypotheses not listed subsequently will be addressed in future reports. 
1. Compared to the previous study, new products are available that push the boundaries of LED equivalency. As LED technology has progressed, the products have gained nominal equivalence to higher and higher wattage incandescent or halogen lamps. Among the earliest products, it was extremely difficult to get enough lumen output for equivalence to a $60 \mathrm{~W}$ incandescent $\mathrm{A}$ lamp, for example. The first two retail lamp studies demonstrated expanding ranges of equivalency, but also that LED lamps still struggled to cover the full range of performance offered by conventional lamps (see Figure 1 and Figure 2). To map recent progress, CALiPER identified six targets, which are listed in Table 1. The target criteria were also informed by a recent CALiPER Snapshot Report on A lamps, which relies on data from LED Lighting Facts. ${ }^{8}$

For each of these categories, CALiPER searched online for products sold by major national retailers including Ace Hardware, Amazon, Costco, Home Depot, IKEA, Lowe's, Menards, Sam's Club, Sears, Target, and Walmart. ${ }^{9}$ The products had to meet certain lumen output thresholds identified by CALiPER, or explicitly claim equivalence to the given product type. Of course, lumen output alone is not enough to determine equivalency or interchangeability, but it is an effective first-pass screening tool. This exercise resulted in a small enough list that CALiPER was able to pursue one product from each represented manufacturer in each category. Where

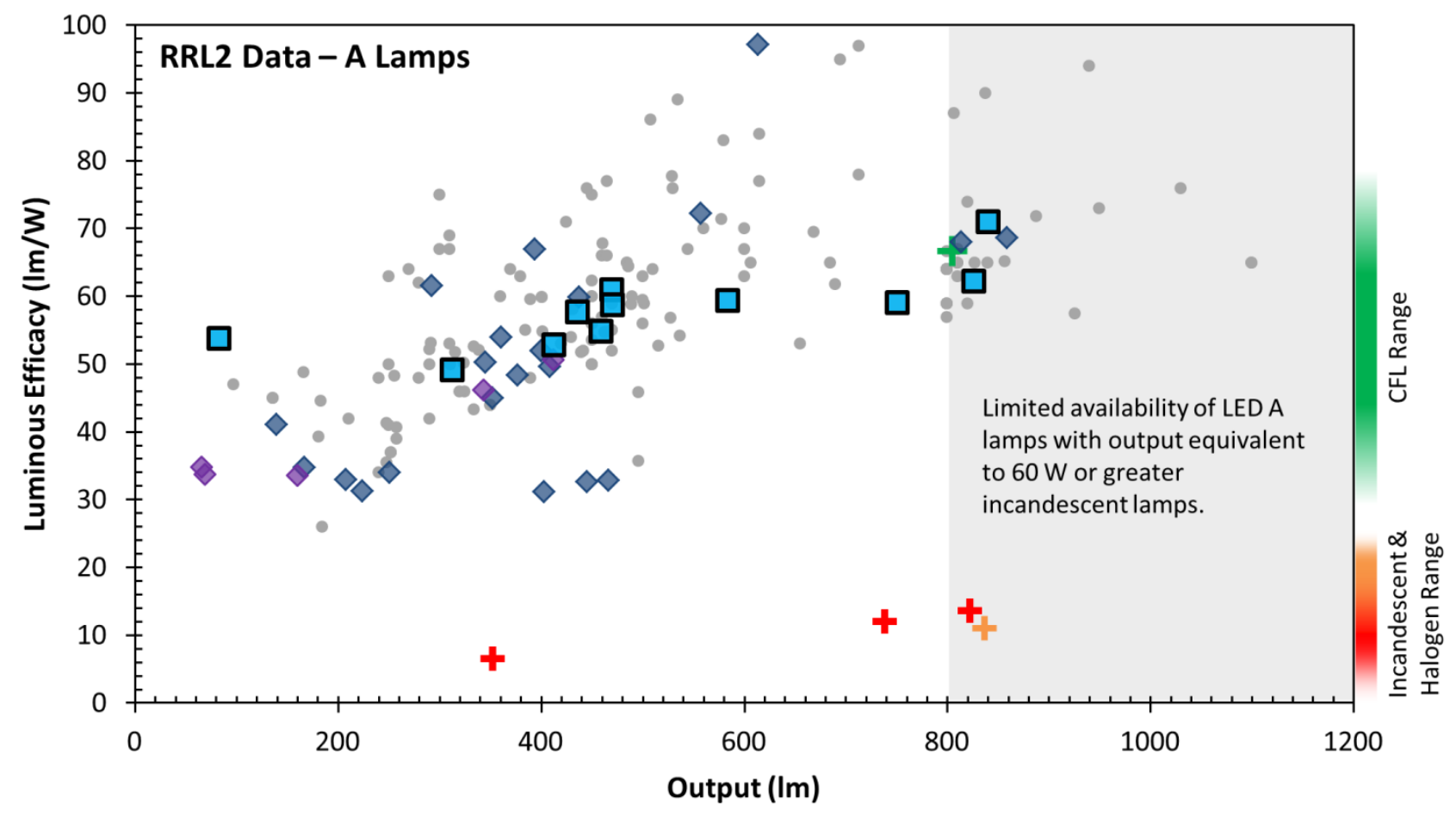

\begin{tabular}{ll}
\hline$\square$ Retail Replacement Lamps, Study 2(2011) & + Incandescent Benchmarks \\
$\diamond$ Retail Replacement Lamps, Study 1(2010) & + Halogen Benchmarks \\
$\diamond$ Other CALiPER Tests (2007-2011) & + CFL Benchmarks \\
- LED Lighting Facts Data (January 2012*) & \\
\hline
\end{tabular}

*Date of download; individual products older.

Figure 1. The results from RRL2 demonstrated the limits of LED A lamps (at the time of the study).

\footnotetext{
${ }^{8}$ Available at: http://apps1.eere.energy.gov/buildings/publications/pdfs/ssl/snapshot2013_a-lamp.pdf

${ }^{9}$ All retailer names trademarked by their respective holders.
} 


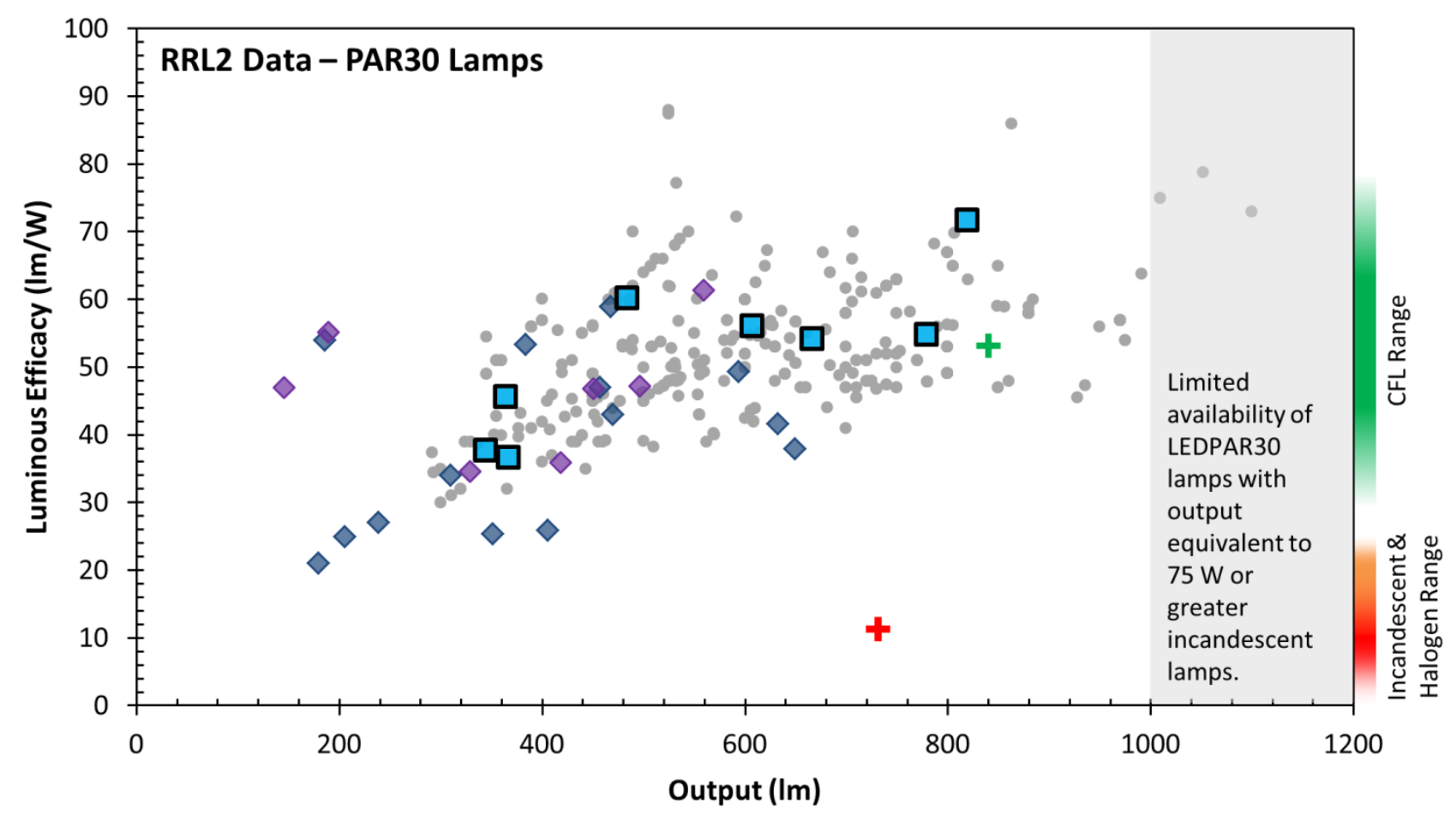

\begin{tabular}{lll}
\hline & Retail Replacement Lamps, Study 2(2011) & + Incandescent Benchmarks \\
$\diamond$ Retail Replacement Lamps, Study 1(2010) & + CFL Benchmarks \\
$\diamond$ Other CALiPER Tests (2007-2011) & \\
- LED Lighting Facts Data (January 2012*) & \\
\hline & *Date of download; individual products older.
\end{tabular}

Figure 2. The results from RRL2 demonstrated the limits of LED PAR30 lamps (at the time of the study).

Table 1. Quantity of LED lamps selected for CALiPER testing in each performance category. Lumen output alone is insufficient for determining equivalency, but it was used as a basic screening criterion to help narrow down the large number of available lamps. Products could qualify for selection by either meeting the output threshold, or making an explicit equivalency claim (regardless of output).

\begin{tabular}{lcc}
\hline & Minimum & Number \\
LED Products Listed as Comparable to: & Output (Im) & Selected \\
\hline 60 W incandescent A lamp (omnidirectional only) & 800 & 15 \\
75 W incandescent A lamp & 1,100 & 5 \\
100 W incandescent A lamp & 1,600 & 2 \\
35 W halogen MR16 lamp (GU5.3 base) & 300 & 6 \\
50 W halogen MR16 lamp (GU5.3 base) & 500 & 3 \\
50 W halogen MR16 lamp (GU10 base) & 400 & 4 \\
75 W halogen PAR30 lamp & 1,000 & 11 \\
\hline
\end{tabular}

1. The minimum output listed does not necessarily represent the output required for equivalency. An intentionally lower number was used to obtain a broader set of lamps. To be chosen, a lamp had to either meet the lumen threshold or make an equivalency claim. 
necessary, CALiPER also purchased benchmark products to supplement its existing database of photometric data for conventional products measured according to LM-79.

For all of the lamps included in this study, preference was given to those products listed as $3000 \mathrm{~K}$ when multiple CCTs were available, with the next closest available CCT chosen otherwise. Given the lack of detailed information about luminous intensity distribution available from retailers, beam angle was not considered during the selection process. The exception to this is $800 \mathrm{~lm} / 60 \mathrm{~W}$-equivalent category, which required an omnidirectional distribution. The final selection resulted in the number of products in each category that is shown in Table 1.

This selection procedure resulted in a set of 46 LED products, some or all of which were used to investigate the remaining issues identified by CALIPER. The sample includes three product types that were also included in both RRL1 and RRL2, covers a similar range of retailers, and is of a similar size, but the selection methodology favors higher-lumen products. Further, unlike several years ago, new LED lamps often augment older models, rather than replace them, to create families of products with multiple lumen-output equivalencies. For example, many manufacturers now have both a $40 \mathrm{~W}(450 \mathrm{~lm})$ and $60 \mathrm{~W}(800 \mathrm{~lm})$ A lamp equivalent. Given these factors, making direct comparisons to older studies is limited for certain metrics, like lumens or input power.

\section{Products available to consumers meet their rated lifetime claims.}

To test this hypothesis, the 15 LED A lamps in the $60 \mathrm{~W}$ incandescent equivalence category were earmarked for additional testing. To this end, these products also had more defined selection criteria, including claimed emission of $800 \mathrm{~lm}$, an omnidirectional distribution, and a nominal CCT of $3000 \mathrm{~K}$ (preferred if available) or $2700 \mathrm{~K}$. The results of this testing will be provided in a subsequent report.

\section{Manufacturer claims and retailer claims for photometric performance are more likely to be met now than they were in RRL2 or RRL1.}

Evaluating performance claims has long been a staple of CALiPER investigations. The retail lamp studies provide an opportunity to track changes in the rates of accurate claims. Despite notable improvement between RRL1 and RRL2, only $55 \%$ of the RRL2 products were within $\pm 10 \%$ of the claimed value for all measured attributes, leaving plenty of room for continued progress. To address this hypothesis, the performance of the 46 lamps chosen for investigating hypothesis one was compared to claimed performance.

\section{Performance has improved since RRL2.}

Regardless of performance relative to claims, it is an important role for CALiPER to track performance over time, especially in this specialized subset of products. However, given that selection parameters for this study differed from previous versions, not all metrics are comparable. The main change that can be tracked is efficacy, but others, like color quality, allow for some limited observations. Likewise, non-photometric performance-such as dimmability, availability of product families, and operability in enclosed fixtures-can be analyzed to some degree, especially when augmenting data from the selected products with data from the full list of potential products. This analysis also allows for identifying conventional lamps that do not yet have an LED counterpart.

\section{Price and price per unit performance has decreased since the last retail lamp study.}

Again, shifting away from a quasi-random sample limits the conclusions that can be drawn about price trends, but it's also possible to use the list of potential products - rather than just the list of selected products - to gain a greater understanding of currently available products. In conjunction, both sets of price data can provide an effective comparison to past data. 


\section{There have been physical changes to the lamp designs, with new optical systems resulting in different luminous intensity distributions.}

Whether or not it is to their best advantage, LED lamps sold at retail stores are currently trying to replicate the performance of existing conventional technologies-while using less energy. At first, few lamps could match the luminous intensity distribution of conventional lamps, especially for omnidirectional A lamps. This generalization is shifting rapidly, however, and photographs show a compelling story of product development.

\section{Product Procurement}

Once a final set of lamps was established according to the previously described objectives, the products were (anonymously) ordered through the Internet from one of the fourteen retailers previously listed. Acquisition occurred in August and September of 2013. If a product was available from multiple locations, it was generally purchased from the location with the lowest price, with some consideration given to diversifying purchase locations. In the end, all 46 products came from just seven different retailers, mostly due to limited selection at many of the aforementioned stores. Table 2 provides data for the included products and retailers, and Figures 3-5 show an image of each lamp. Manufacturer and product names are provided in Appendix B.

Table 2. A comparison of products included in the three CALiPER retail lamp studies. For Study 3, the retailers with an asterisk represent the actual stores where the products were purchased, as opposed to stores that were surveyed. Some products that were purchased from a specific retailer were also available at other stores.

\begin{tabular}{|c|c|c|c|c|c|c|}
\hline & \multicolumn{2}{|c|}{ Retail Lamps Study 1 (RRL1) } & \multicolumn{2}{|c|}{ Retail Lamps Study 2 (RRL2) } & \multicolumn{2}{|c|}{ Retail Lamps Study 3 (RRL3) } \\
\hline Purchase: & July \& August 2010 & & November 2011 & & September \& October 2 & \\
\hline Products: & 33 & & 38 & & 46 & \\
\hline Product & MR16/PAR16 & 11 & MR16/PAR16 GU10 & 9 & MR16 (GU5.3 \& GU10) & 13 \\
\hline \multirow[t]{5}{*}{ Types: } & PAR30 & 7 & PAR30 & 8 & PAR30 & 9 \\
\hline & A19 & 5 & A19 & 11 & A19 & 24 \\
\hline & PAR20 & 4 & PAR20 & 5 & & \\
\hline & B10 (candelabra) & 4 & $\mathrm{G} 25$ & 5 & & \\
\hline & C7 (night light) & 2 & & & & \\
\hline \multirow[t]{14}{*}{ Retailers: } & Ace Hardware & & Ace Hardware & & Ace Hardware & \\
\hline & BJs & & Amazon & & Amazon* & \\
\hline & Home Depot & & BJs & & Best Buy* & \\
\hline & Lowe's & & Costco & & Costco & \\
\hline & Sam's Club & & Home Depot & & Fred Meyer (Kroger) & \\
\hline & Sears & & Lowe's & & Grainger* & \\
\hline & Target & & Menards & & Home Depot* & \\
\hline & Walmart & & Target & & Ikea & \\
\hline & & & Walmart & & Lowe's* & \\
\hline & & & & & Menards* & \\
\hline & & & & & Sam's Club & \\
\hline & & & & & Sears & \\
\hline & & & & & Target & \\
\hline & & & & & Walmart* & \\
\hline
\end{tabular}



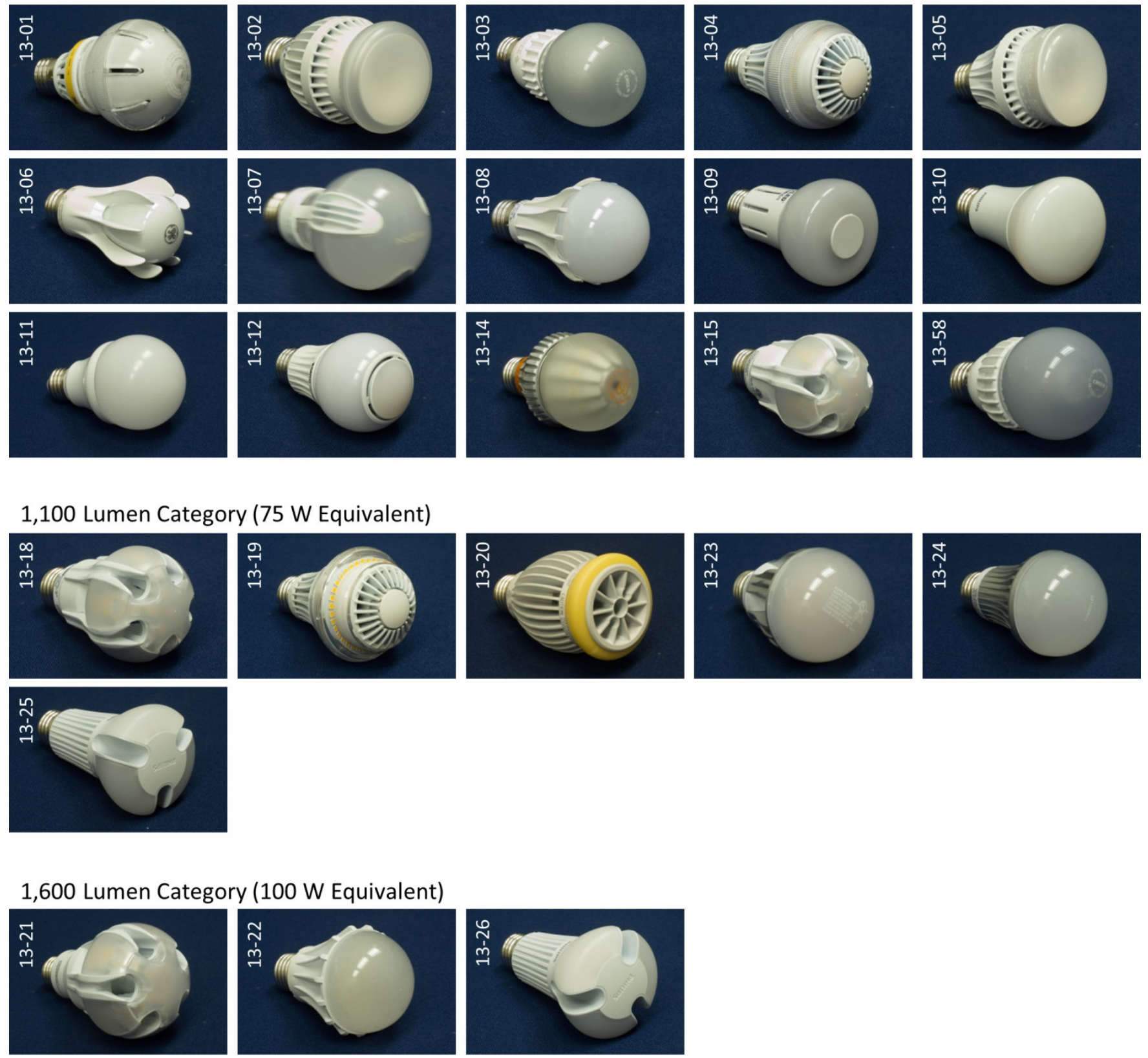

Figure 3. A lamps included in RRL3, divided by lumen output category. At least four manufacturers have products in more than one of the included categories. For this report, CALiPER did not test any products in the 450 lumen ( $40 \mathrm{~W}$ equivalent) category. These photographs should not be used to evaluate the relative size of the lamps. 

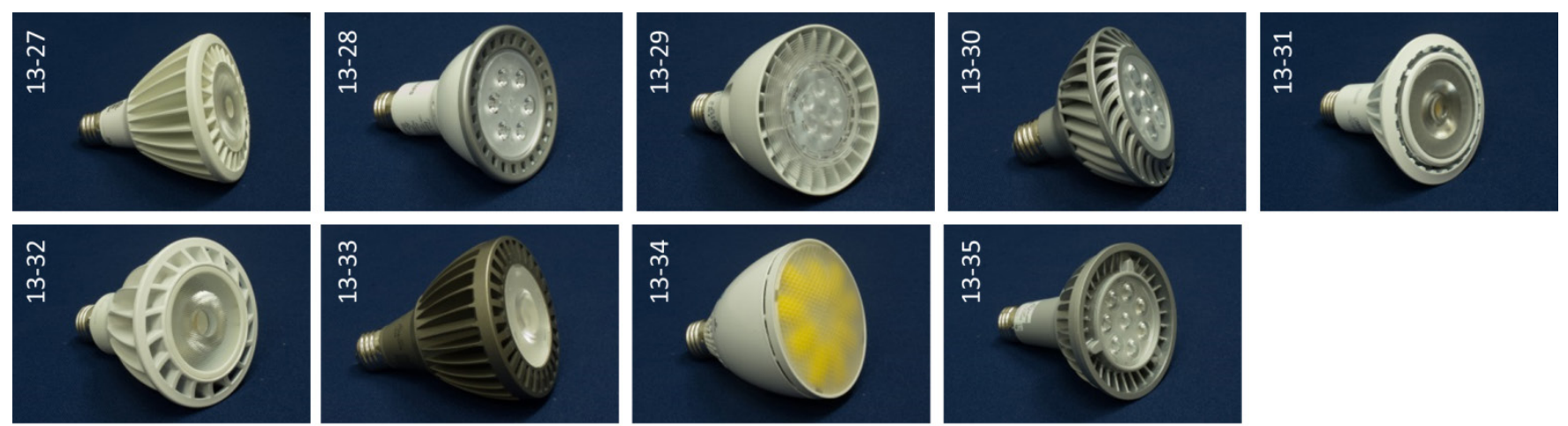

Figure 4. PAR30 lamps included in RRL3. All lamps except 13-34 claimed to be approximately equivalent to a 75 W halogen PAR30. Product 13-34 claimed equivalence to a $60 \mathrm{~W}$ halogen PAR30. These photographs should not be used to evaluate the relative size of the lamps.
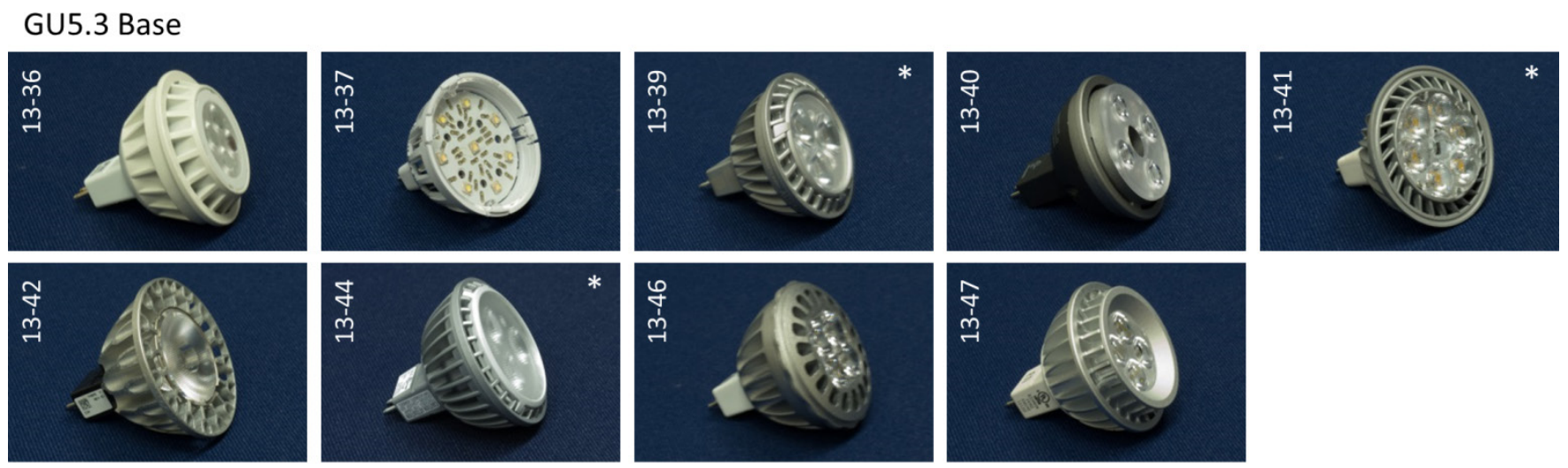

\section{GU10 Base}
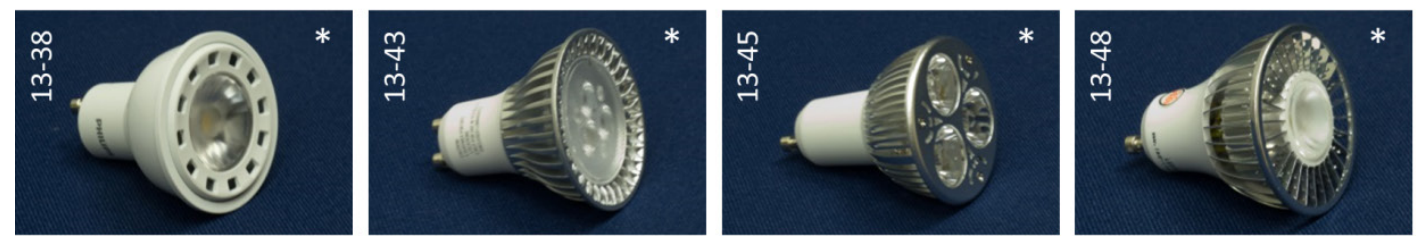

Figure 5. MR16 lamps included in RRL3, divided by base type. Lamps with an asterisk claimed equivalence to a $50 \mathrm{~W}$ halogen MR16, while the remainder claimed equivalence to a $35 \mathrm{~W}$ halogen MR16-four products did not make a claim, but were included based on their lumen output. These photographs should not be used to evaluate the relative size of the lamps. 


\section{Results}

\section{CALIPER LED Test Data}

\section{Current Results: 2013 Retail Replacement Lamp Study}

After purchasing and processing by CALiPER, the 46 lamps in this series were sent to independent photometric laboratories for testing. Three samples of each lamp were photometered in an integrating sphere, following the IES LM-79-08 test procedure. One of those samples was also measured using a goniophotometer in order to provide information about the luminous intensity distribution.

The values presented in Table 3 are the mean of the data obtained using the integrating sphere, where possible. One exception is $D_{u v}$, which is reported as the value furthest from zero. Data pertaining to the luminous intensity distribution is the single value measured using the goniophotometry method. There was less consistency between measured values for the three samples than is typically seen by CALiPER, although most other series include only two samples of each product. While the mean range of the lowest and highest measurements was only $\pm 2.5 \%$ of the average value, three products (13RT-22, 13RT-29, and 13RT-34) had a range of more than $\pm 5 \%$-in other words, a range that was more than $10 \%$ of the average value, which is still unlikely to be noticed by most people. Poor product-to-product consistency is concerning.

Table 3. Results of CALiPER tests for the RRL3 lamps. For a glossary of terms used in this report, see Appendix A. The brand and model for each product are identified in Appendix B.

\begin{tabular}{|c|c|c|c|c|c|c|c|c|c|c|c|}
\hline $\begin{array}{l}\text { DOE } \\
\text { CALiPER } \\
\text { Test ID }\end{array}$ & Group $^{1}$ & $\begin{array}{c}\text { Cost } \\
(\$)\end{array}$ & $\begin{array}{c}\text { Initial } \\
\text { Output } \\
\text { (Im) }\end{array}$ & $\begin{array}{c}\text { Input } \\
\text { Power } \\
\text { (W) }\end{array}$ & $\begin{array}{l}\text { Efficacy } \\
(\mathrm{Im} / \mathrm{W})\end{array}$ & $\begin{array}{l}\text { Power } \\
\text { Factor }\end{array}$ & CRI & $\begin{array}{l}\text { CCT } \\
(\mathrm{K})\end{array}$ & $D_{u v}$ & $\begin{array}{c}\text { CBCP } \\
\text { (cd) }\end{array}$ & $\begin{array}{c}\text { Beam } \\
\text { Angle } \\
\text { (deg) }\end{array}$ \\
\hline 13RT-01 & A19-60 & $\$ 18.87$ & 846 & 13.0 & 65 & 1.00 & 81 & 2989 & -0.0017 & - & - \\
\hline 13RT-02 & A19-60 & $\$ 37.30$ & 757 & 11.4 & 66 & 0.82 & 83 & 2932 & -0.0012 & - & - \\
\hline 13RT-03 & A19-60 & $\$ 9.97$ & 843 & 9.7 & 87 & 0.98 & 82 & 2784 & -0.0017 & - & - \\
\hline 13RT-04 & A19-60 & $\$ 19.97$ & 910 & 11.0 & 83 & 0.95 & 83 & 3008 & -0.0023 & - & - \\
\hline 13RT-05 & A19-60 & $\$ 14.99$ & 865 & 13.0 & 66 & 0.90 & 83 & 3012 & -0.0019 & - & - \\
\hline 13RT-06 & A19-60 & $\$ 47.62$ & 784 & 13.4 & 58 & 1.00 & 84 & 2993 & 0.0020 & - & - \\
\hline 13RT-07 & A19-60 & $\$ 17.99$ & 852 & 13.1 & 65 & 0.84 & 80 & 3022 & 0.0019 & - & - \\
\hline 13RT-08 & A19-60 & $\$ 45.00$ & 708 & 9.9 & 72 & 0.83 & 87 & 2779 & -0.0025 & - & - \\
\hline 13RT-09 & A19-60 & $\$ 18.49$ & 870 & 11.4 & 77 & 0.99 & 84 & 2978 & -0.0014 & - & - \\
\hline $13 R T-10$ & A19-60 & $\$ 16.97$ & 882 & 11.0 & 80 & 0.92 & 80 & 2618 & -0.0008 & - & - \\
\hline 13RT-11 & A19-60 & $\$ 8.88$ & 863 & 9.5 & 91 & 0.81 & 82 & 2669 & -0.0026 & - & - \\
\hline $13 R T-12$ & A19-60 & $\$ 40.95$ & 838 & 9.8 & 86 & 0.97 & 82 & 2680 & -0.0035 & - & - \\
\hline $13 R T-13$ & A19-60 & $\$ 49.99$ & 836 & 13.5 & 62 & 0.94 & 79 & 2806 & -0.0018 & - & - \\
\hline 13RT-14 & A19-60 & $\$ 21.98$ & 918 & 13.0 & 71 & 0.96 & 83 & 2696 & -0.0058 & - & - \\
\hline 13RT-58 & A19-60 & $\$ 18.30$ & 807 & 12.7 & 64 & 0.98 & 92 & 2726 & -0.0017 & - & - \\
\hline
\end{tabular}

1. Group codes indicate the shape, size, and equivalency claim as considered in this report. A few equivalency claims varied based on the data source. 
Table 3. (continued)

\begin{tabular}{|c|c|c|c|c|c|c|c|c|c|c|c|}
\hline $\begin{array}{l}\text { DOE } \\
\text { CALiPER } \\
\text { Test ID }\end{array}$ & Group $^{1}$ & $\begin{array}{l}\text { Cost } \\
(\$)\end{array}$ & $\begin{array}{c}\text { Initial } \\
\text { Output } \\
\text { (Im) }\end{array}$ & $\begin{array}{c}\text { Input } \\
\text { Power } \\
\text { (W) }\end{array}$ & $\begin{array}{l}\text { Efficacy } \\
(\mathrm{Im} / \mathrm{W})\end{array}$ & $\begin{array}{l}\text { Power } \\
\text { Factor }\end{array}$ & CRI & $\begin{array}{l}\text { CCT } \\
(\mathrm{K})\end{array}$ & $D_{u v}$ & $\begin{array}{c}\text { CBCP } \\
\text { (cd) }\end{array}$ & $\begin{array}{l}\text { Beam } \\
\text { Angle } \\
\text { (deg) }\end{array}$ \\
\hline 13RT-18 & A19-75 & $\$ 39.98$ & 976 & 15.8 & 62 & 0.96 & 83 & 2736 & -0.0049 & - & - \\
\hline 13RT-19 & A19-75 & $\$ 34.97$ & 1,409 & 13.4 & 105 & 0.97 & 80 & 2724 & -0.0013 & - & - \\
\hline 13RT-20 & A19-75 & $\$ 24.98$ & 1,140 & 17.1 & 67 & 0.94 & 82 & 3089 & -0.0022 & - & - \\
\hline $13 R T-23$ & A19-75 & $\$ 16.00$ & 995 & 13.7 & 73 & 0.82 & 82 & 2705 & -0.0026 & - & - \\
\hline 13RT-24 & A19-75 & $\$ 25.99$ & 627 & 9.2 & 68 & 0.76 & 82 & 3006 & -0.0033 & - & - \\
\hline $13 R T-25$ & A21-75 & $\$ 29.97$ & 1,112 & 15.5 & 72 & 0.94 & 80 & 2673 & -0.0015 & - & - \\
\hline 13RT-21 & A21-100 & $\$ 35.98$ & 1,613 & 20.8 & 78 & 0.98 & 82 & 2733 & -0.0047 & - & - \\
\hline $13 R T-22$ & A19-100 & $\$ 20.24$ & 521 & 6.2 & 84 & 0.60 & 52 & 3115 & 0.0058 & - & - \\
\hline 13RT-26 & A21-100 & $\$ 34.97$ & 1,568 & 19.9 & 79 & 0.96 & 81 & 2667 & -0.0024 & - & - \\
\hline 13RT-27 & PAR30 & $\$ 49.98$ & 959 & 16.5 & 58 & 0.77 & 92 & 3021 & 0.0028 & 2,972 & 25 \\
\hline 13RT-28 & PAR30 & $\$ 29.97$ & 817 & 12.5 & 65 & 0.75 & 85 & 3010 & -0.0004 & 3,654 & 23 \\
\hline 13RT-29 & PAR30 & $\$ 31.97$ & 770 & 11.5 & 67 & 0.92 & 84 & 3121 & -0.0033 & 1,455 & 32 \\
\hline 13RT-30 & PAR30 & $\$ 37.97$ & 781 & 13.5 & 58 & 0.94 & 83 & 2676 & -0.0024 & 2,293 & 33 \\
\hline 13RT-31 & PAR30 & $\$ 25.99$ & 813 & 14.0 & 58 & 0.93 & 82 & 3016 & -0.0006 & 1,504 & 35 \\
\hline 13RT-32 & PAR30 & $\$ 45.02$ & 940 & 14.0 & 67 & 0.91 & 83 & 3040 & -0.0029 & 1,952 & 38 \\
\hline 13RT-33 & PAR30 & $\$ 79.90$ & 883 & 14.8 & 60 & 0.90 & 83 & 3013 & 0.0008 & 1,831 & 37 \\
\hline $13 R T-34$ & PAR30 & $\$ 19.99$ & 669 & 9.5 & 70 & 0.98 & 83 & 2822 & $-0.0083^{2}$ & 212 & 110 \\
\hline 13RT-35 & PAR30 & $\$ 47.35$ & 732 & 15.8 & 46 & 0.78 & 82 & 3075 & -0.0023 & 3,583 & 22 \\
\hline $13 R T-36$ & MR16-35 & $\$ 19.98$ & 340 & 6.3 & 54 & 0.93 & 81 & 2980 & -0.0017 & 855 & 32 \\
\hline 13RT-37 & MR16-35 & $\$ 13.99$ & 294 & 6.0 & 49 & 0.60 & 89 & 3033 & -0.0034 & 118 & 104 \\
\hline $13 R T-40$ & MR16-35 & $\$ 23.97$ & 488 & 9.8 & 50 & 0.96 & 85 & 2674 & -0.0012 & 2,021 & 24 \\
\hline 13RT-42 & MR16-35 & $\$ 35.08$ & 351 & 9.9 & 36 & 0.93 & 96 & 3030 & 0.0008 & 882 & 35 \\
\hline $13 R T-46$ & MR16-35 & $\$ 37.90$ & 394 & 6.4 & 61 & 0.67 & 83 & 3000 & -0.0006 & 1,084 & 36 \\
\hline $13 R T-47$ & MR16-35 & $\$ 27.98$ & 351 & 7.5 & 47 & 0.65 & 81 & 3141 & 0.0034 & 1,627 & 18 \\
\hline 13RT-39 & MR16-50 & $\$ 29.97$ & 496 & 6.6 & 75 & 0.67 & 84 & 3058 & -0.0020 & 2,833 & 20 \\
\hline 13RT-41 & MR16-50 3 & $\$ 29.97$ & 438 & 6.6 & 67 & 0.97 & 82 & 2982 & -0.0016 & 1,937 & 21 \\
\hline 13RT-44 & MR16-50 & $\$ 30.75$ & 515 & 7.2 & 71 & 0.70 & 82 & 3075 & -0.0022 & 1,276 & 31 \\
\hline $13 R T-38$ & MR16-504 & $\$ 29.97$ & 300 & 5.6 & 54 & 0.77 & 85 & 3019 & -0.0007 & 921 & 25 \\
\hline $13 R T-43$ & MR16-50 & $\$ 13.57$ & 237 & 4.2 & 56 & 0.97 & 83 & 3021 & 0.0011 & 426 & 39 \\
\hline 13RT-45 & MR16-50 & $\$ 32.99$ & 251 & 3.6 & 70 & 0.60 & 73 & 6411 & -0.0015 & 551 & 38 \\
\hline 13RT-48 & MR16-504 & $\$ 39.48$ & 260 & 5.3 & 49 & 0.62 & 87 & 5954 & 0.0023 & 470 & 32 \\
\hline Minimum & & $\$ 8.88$ & 237 & 3.6 & 36 & 0.60 & 52 & 2618 & - & 118 & 18 \\
\hline Mean & & $\$ 30.09$ & 752 & 11.2 & 67 & 0.86 & 83 & 3050 & - & 1,566 & 37 \\
\hline Maximum & & $\$ 79.90$ & 1,613 & 20.8 & 105 & 1.00 & 96 & 6411 & - & 3,654 & 110 \\
\hline
\end{tabular}

Notes:

1. Group codes indicate the shape, size, and equivalency claim as considered in this report. A few equivalency claims varied based on the data source.

2. Value outside of ANSI-defined limits (ANSI C78.377).

3. Tested at 12 VDC. All other MR16s tested AC.

4. Products with a GU10 base, tested at $120 \mathrm{~V}$. All other MR16s tested at $12 \mathrm{~V}$. 


\section{Past CALIPER Data}

From 2007 through 2011, CALiPER purchased numerous products marketed as replacements for conventional A19, MR16, or PAR30 lamps, and conducted two other studies on lamps sold at retail stores. Few of those products, however, would be competitive with the products purchased in late 2013 for this report. For comparison purposes, data points for previously tested products are shown in some figures within this report; numerical data for those products is shown in Appendix B.

\section{Supplemental LED Lamp Data LED Lighting Facts}

LED Lighting Facts is a voluntary listing program that requires test data be obtained according to LM-79-08. Because it does not have qualification criteria, the data may be more representative of the complete LED market. However, the data may or may not be representative of products sold through retail stores. Table 4 provides summary data for products listed by LED Lighting Facts as of January 2014. Note that legacy classification data makes it difficult to separate the types of MR16 lamps considered in this report; more detailed submission requirements instituted in 2013 should address this issue in the future.

The same summary data was captured for RRL2, and comparing the two datasets indicates substantial development in the past two years. For each category, there are more than 100 additional products listed, which is a notable achievement since LED Lighting Facts now deactivates products if they are not renewed by the manufacturer on an annual basis. Further, in each category, mean efficacy increased by 7-9 Im/W, and mean output increased by over $100 \mathrm{~lm}$. The maximum values also increased for these categories. As a net result, mean input power increased somewhat for each category, despite greater energy efficiency. For color quality, the CRI statistics did not change much, but the mean CCT dropped for all three categories. A lower percentage of higherCCT products indicates a closer resemblance to conventional lamps. In terms of electrical quality, the mean power factor was higher for all three categories than it was in late 2011.

Table 4. Summary statistics for products listed by LED Lighting Facts as of January 2014. Performance has increased substantially since RRL2.

\begin{tabular}{|c|c|c|c|c|c|c|c|c|}
\hline Type & $\begin{array}{l}\text { Number of } \\
\text { Products }\end{array}$ & & $\begin{array}{c}\text { Initial } \\
\text { Output } \\
\text { (Im) }\end{array}$ & $\begin{array}{l}\text { Total } \\
\text { Input } \\
\text { Power } \\
\text { (W) }\end{array}$ & $\begin{array}{c}\text { Efficacy } \\
(\mathrm{Im} / \mathrm{W})\end{array}$ & CRI & $\begin{array}{l}\text { CCT } \\
(\mathrm{K})\end{array}$ & $\begin{array}{l}\text { Power } \\
\text { Factor }^{1}\end{array}$ \\
\hline & & Minimum & 136 & 3.0 & 37 & 63 & 2619 & 0.24 \\
\hline \multirow[t]{3}{*}{ A19 } & 355 & Mean & 720 & 10.3 & 70 & 82 & 3272 & 0.87 \\
\hline & & Maximum & 1,780 & 23.0 & 99 & 94 & 7177 & 1.00 \\
\hline & & Minimum & 292 & 6.9 & 32 & 63 & 2654 & 0.51 \\
\hline \multirow[t]{3}{*}{ PAR30 } & 452 & Mean & 750 & 12.7 & 60 & 83 & 3204 & 0.88 \\
\hline & & Maximum & 1,250 & 18.0 & 100 & 96 & 6352 & 1.00 \\
\hline & & Minimum & 69 & 1.6 & 23 & 51 & 2666 & 0.50 \\
\hline \multirow[t]{2}{*}{ MR16 } & 461 & Mean & 335 & 6.2 & 54 & 83 & 3182 & 0.81 \\
\hline & & Maximum & 606 & 13.0 & 85 & 97 & 6789 & 1.00 \\
\hline
\end{tabular}

1. Power Factor is not a required metric, and is not provided for all listings. 
Table 5. ENERGY STAR qualification requirements for A, PAR30, and MR16 lamps, effective September 2014. Although they are not yet effective, these requirements are shown in subsequent figures.

\begin{tabular}{|c|c|c|c|c|c|c|}
\hline $\begin{array}{l}\text { Lamp } \\
\text { Type }\end{array}$ & $\begin{array}{l}\text { Initial Output } \\
(\mathrm{Im})\end{array}$ & $\begin{array}{c}\text { Luminous } \\
\text { Intensity Distribution }\end{array}$ & $\begin{array}{l}\text { Efficacy } \\
(\mathrm{Im} / \mathrm{W})\end{array}$ & $\begin{array}{l}\text { Power } \\
\text { Factor }\end{array}$ & CRI & $\begin{array}{r}\text { CCT } \\
(\mathrm{K}) \\
\end{array}$ \\
\hline A & $\begin{aligned} 200+ & =25 \mathrm{~W} \text { Incandescent } \\
325+ & =35 \mathrm{~W} \text { Incandescent } \\
450+ & =40 \mathrm{~W} \text { Incandescent } \\
800+ & =60 \mathrm{~W} \text { Incandescent } \\
1,100+ & =75 \mathrm{~W} \text { Incandescent } \\
1,600+ & =100 \mathrm{~W} \text { Incandescent }\end{aligned}$ & $\begin{array}{l}90 \% \text { of measured luminous } \\
\text { intensity values shall be } \\
\text { within } 25 \% \text { of the average } \\
\text { value. All values within } 50 \% \\
\text { of average. At least } 5 \% \text { of flux } \\
\text { in the } 135^{\circ} \text { to } 180^{\circ} \text { zone. }\end{array}$ & $\begin{array}{c}55 \\
(<15 \mathrm{~W}) \\
65 \\
(\geq 15 \mathrm{~W})\end{array}$ & 0.70 & 80 & $\begin{array}{l}2700 \\
3000 \\
3500 \\
4000 \\
5000 \\
6500\end{array}$ \\
\hline MR & $\begin{array}{c}\text { No Requirement } \\
\text { Based on Center Beam Intensity }\end{array}$ & No Requirement & $\begin{array}{c}40 \\
(<20 \mathrm{~W}) \\
50 \\
(\geq 20 \mathrm{~W})\end{array}$ & 0.70 & 80 & $\begin{array}{l}2700 \\
3000 \\
3500 \\
4000 \\
5000 \\
6500\end{array}$ \\
\hline PAR & $\begin{array}{c}\text { No Requirement } \\
\text { Based on Center Beam Intensity }\end{array}$ & No Requirement & $\begin{array}{c}40 \\
(<20 \mathrm{~W}) \\
50 \\
(\geq 20 \mathrm{~W})\end{array}$ & 0.70 & 80 & $\begin{array}{l}2700 \\
3000 \\
3500 \\
4000 \\
5000 \\
6500\end{array}$ \\
\hline
\end{tabular}

At some point, lumen output gains can be expected to diminish, as even conventional lamps in these form factors have practical reasons for the range in output. Likewise, CCT and power factor can be expected to stabilize relatively soon. Two interesting trends to watch will be CRI and efficacy/input power. Higher-CRI products may become more prevalent, especially given recent efforts to include higher CRI thresholds for qualification programs. The potential for efficacy increases is still large, even though (high-quality) LEDs are generally the most efficient source currently available. Asymptotic lumen output and increasing efficacy should allow for lower input power, reversing the current trend toward higher power (and higher output) products.

\section{ENERGY STAR}

ENERGY STAR is a consumer-focused program, and thus has strong relevance to the data collected in this report. However, ENERGY STAR is a qualification program, and not all products sold at stores are required to meet the criteria. The performance requirements, shown in Table 5, provide a tool for analyzing the data in this report, but they should not be taken to represent an outstanding product. There are many criteria for which performance thresholds cannot be specified, and many available LED products substantially exceed the ENERGY STAR efficacy thresholds, for example. Table 6 shows summary statistics for the qualified products -in the relevant categories-as of January 2014. 
Table 6. Summary statistics for relevant products listed by ENERGY STAR as of January 2014.

\begin{tabular}{|c|c|c|c|c|c|c|c|c|c|c|c|}
\hline Type & $\begin{array}{c}\text { Number } \\
\text { of } \\
\text { Products }\end{array}$ & $\begin{array}{l}\text { Dimming } \\
\text { (\% total) }\end{array}$ & & $\begin{array}{c}\text { Initial } \\
\text { Output } \\
\text { (Im) }\end{array}$ & $\begin{array}{c}\text { Total } \\
\text { Input } \\
\text { Power } \\
\text { (W) }\end{array}$ & $\begin{array}{c}\text { Efficacy } \\
(\mathrm{Im} / \mathrm{W})\end{array}$ & CRI & $\begin{array}{l}\mathrm{CCT} \\
(\mathrm{K}) \\
\end{array}$ & $\begin{array}{l}\text { Power } \\
\text { Factor }\end{array}$ & $\begin{array}{c}\text { Rated } \\
\text { Life } \\
\text { (hrs) }\end{array}$ & $\begin{array}{c}\text { Warranty } \\
\text { (years) }\end{array}$ \\
\hline & & & Min & 450 & 6.0 & 50 & 80 & 2700 & 0.70 & 25,000 & 3.0 \\
\hline \multirow[t]{3}{*}{ A19 } & 266 & $94 \%$ & Mean & 790 & 11.6 & 67 & 83 & 2930 & 0.90 & 27,726 & 4.1 \\
\hline & & & Max & 1,780 & 27.0 & 101 & 93 & 4000 & 0.99 & 50,000 & 16.0 \\
\hline & & & Min & 200 & 4.5 & 39 & 80 & 2700 & 0.53 & 20,000 & 3.0 \\
\hline \multirow[t]{3}{*}{ PAR30 } & 1,651 & $92 \%$ & Mean & 812 & 13.7 & 59 & 83 & 3045 & 0.88 & 30,851 & 4.0 \\
\hline & & & Max & 2,000 & 26.0 & 89 & 94 & 4000 & 1.00 & 50,000 & 20.0 \\
\hline & & & Min & 139 & 3.0 & 40 & 80 & 2700 & 0.50 & 20,000 & 3.0 \\
\hline MR16 & 257 & $60 \%$ & Mean & 326 & 5.8 & 55 & 84 & 2994 & 0.78 & 28,230 & 3.6 \\
\hline \multirow[t]{2}{*}{ GU5.3 } & & & Max & 620 & 10.0 & 81 & 90 & 4000 & 1.00 & 50,000 & 10.0 \\
\hline & & & Min & 200 & 3.8 & 49 & 80 & 2700 & 0.53 & 25,000 & 3.0 \\
\hline MR16 & 96 & $77 \%$ & Mean & 311 & 5.6 & 56 & 82 & 3033 & 0.76 & 31,146 & 3.7 \\
\hline GU10 & & & Max & 500 & 8.0 & 78 & 87 & 4000 & 0.98 & 50,000 & 10.0 \\
\hline
\end{tabular}

The summary data from LED Lighting Facts and ENERGY STAR is comparable. The most notable difference is that ENERGY STAR excludes products that do not meet the criteria (e.g., low efficacy, low lumen output, high CCT, etc.).

\section{CALiPER Testing of Conventional Product Benchmarks}

In order to evaluate equivalency, CALiPER also tests conventional products using the IES LM-79-08 procedure. Included in those products are 15 A lamps-or "household" bulbs-seven MR16 lamps, and three PAR30 lamps that correspond to the range of LED products tested for this report. The summary data for these lamps is provided in Appendix C.

For the A lamp category, incandescent, halogen, and CFL products have been tested. As of 2014, the manufacturing and importing of all wattages of general purpose, standard incandescent A lamps is prohibitedregulations for higher wattages (e.g., $75 \mathrm{~W}, 100 \mathrm{~W}$ ) took effect earlier. This limited CALiPER's ability to test these products with the RRL3 group, although some earlier test data was available. Consumers will face a similar situation as existing stocks are depleted, and will now choose among halogen, CFL, and LED lamps. Although conventional $40 \mathrm{~W}$ and $60 \mathrm{~W}$ incandescent lamps dominate the residential market, it is now very important that more energy-efficient lamps cover the full range that was available from incandescent lamps, including $75 \mathrm{~W}$, $100 \mathrm{~W}$, and three-way lamps, among others. 


\section{Analysis}

\section{Size, Shape, and Form Factor}

The form factor of most LED lamps has evolved as they have developed, in part due to increasing efficacy, which in turn results in less mass and/or volume needed for thermal management. In all three product types included in this report, this trend has been apparent. Nonetheless, there are certain designs that have seen very little updating over time, other than inclusion of more efficient LED packages. In a few cases, the same products that were available in 2011 were still available in 2013. ${ }^{10}$ Figure 6 demonstration the progression for three example product pairs for which the same brand and product type was tested in both RRL2 and RRL3.

For A lamps, there has been a notable increase in the availability of products with an omnidirectional emission. Although some products were available with this characteristic in 2011, many were semi-directional-or "snowcones" - that emitted light predominantly in one direction. For example, 7 of the $11 \mathrm{~A}$ lamps tested for RRL2 were not designed to have an omnidirectional distribution, although luminous intensity distribution was not specifically measured by CALiPER. Importantly, semi-directional lamps are still on the market today-and they may work well in some applications-but they were not chosen for RRL3 based on the selection parameters. In some cases, an omnidirectional lamp has been added to an existing product line, and in other cases it has replaced the existing product. As shown previously in the photographs in Figure 3, omnidirectional emission has been accomplished using a wide variety of optical systems, the performance of which will be explored in subsequent sections of this report.
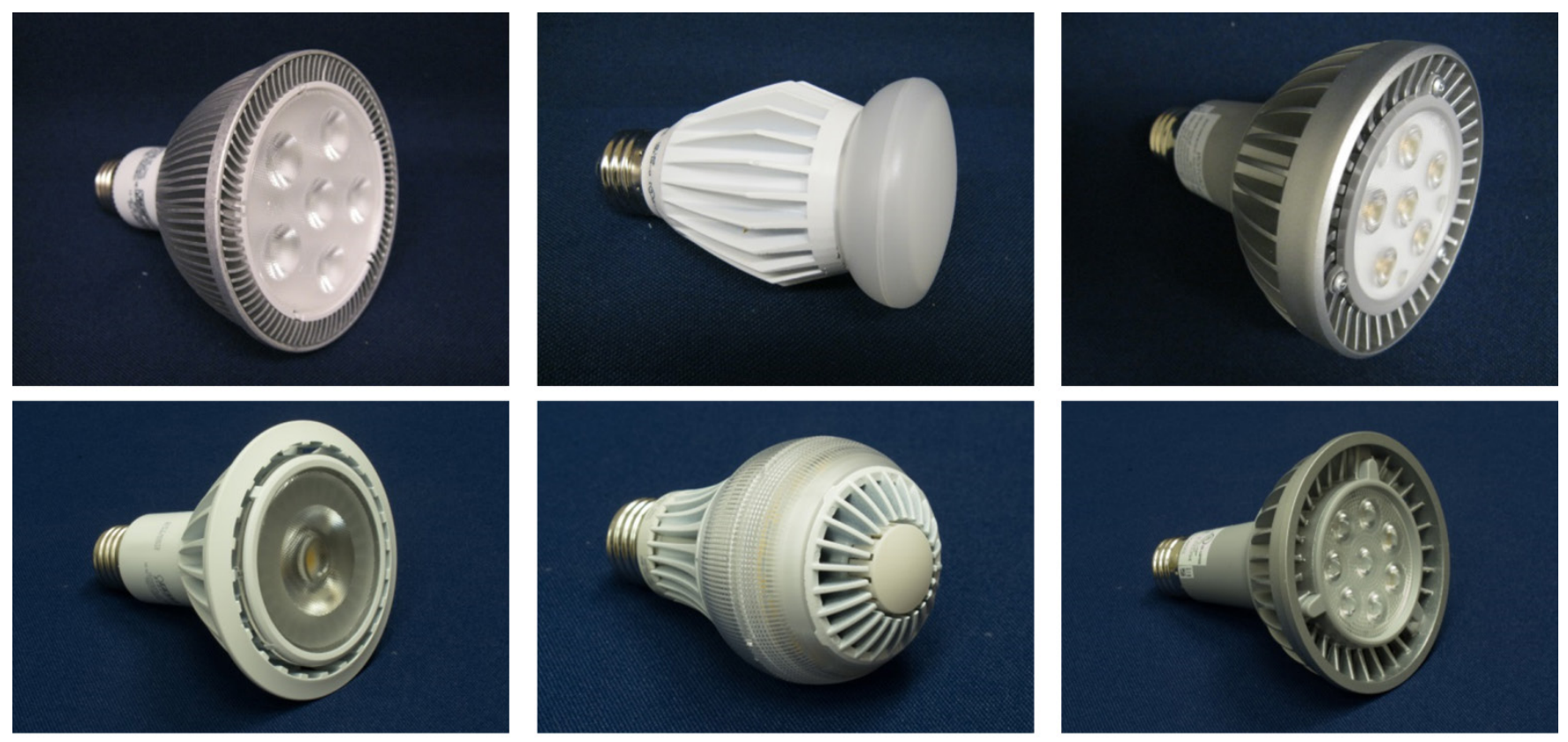

Figure 6. Comparison of three example pairs of products, with one from RRL2 (top) and the other from RRL3 (bottom), with each pair representing one manufacturer. Many product lines have seen substantial changes in the past two years, whereas others have not changed much at all.

\footnotetext{
${ }^{10}$ For example, product 13RT-48 was indistinguishable from 11RT-71, but sold under a different brand name.
} 
Despite the range of designs, all of the RRL3 A lamps were within the ANSI defined dimensions for A19 or A21 lamps, as appropriate. ${ }^{11}$ This is in contrast to RRL2, when 6 of $11 \mathrm{~A}$ lamps tested exceeded the maximum allowable length for an A19 lamp. Given that few of the LED lamps available today utilize an overall form factor similar to an incandescent lamp, and that consumers may be unfamiliar with the A19 designation, some retailers and manufacturers have begun using the name household bulb. This is just one example of the emergence of LEDs causing the lighting industry to rethink nomenclature.

Directional emission, as is characteristic of PAR30 and MR16 lamps, is inherently easier to achieve with LEDs, which has resulted in less diversity of product designs. The most notable difference among a majority of products in the PAR30 category is whether they have a single emitter or multiple emitters. Four of the RRL3 products were single-emitters, which a recent CALiPER investigation showed to have preferred beam quality, ${ }^{12}$ whereas five used multiple emitters. Most of the MR16 lamps used more than one emitter, but a few products used a single emitter. For RRL2, a similar number of single-emitter lamps was found for MR16s, but none of the PAR30s used a single-emitter design-although two PAR20s did. The various trends for single-emitter versus multi-emitter designs are likely a result of the form factors and lumen package demands of the different product types.

In terms of shape and size, the directional lamps were not as good as the A lamps at meeting ANSI standards. One of the PAR30 lamps was not within the allowable dimensions, and four others were outside the dimensions but within the measurement tolerance $( \pm 5 \%)$. One challenge with PAR30 lamps is the difference between longneck and short-neck versions; many retailers and manufacturers do not specify either category, which could make it difficult for a consumer to get an appropriate lamp for a specific fixture. As for MR16s, ANSI only specifies dimensions for those with a GU5.3 base. For RRL3, three of the MR16, GU5.3 products exceeded the maximum allowable length by more than $5 \%$, and four additional products exceeded the length by less than $5 \%$. Only one product was under the length limit (13RT-37). This result for MR16s is probably a result of the small size, which is very demanding given the components necessary within an integral LED lamp. All products-both PAR30 and MR16-met ANSI requirements for diameter.

\section{Lumen Output, Efficacy, and Distribution Characteristics}

At the core of product equivalency are lumen output and luminous intensity distribution, which is not to diminish the importance of color quality, power quality, and all the other characteristics that are important to lighting systems. Many high-quality LED products are available to specifiers, but are those same products available at retail stores? Can retail LED lamps cover the range of performance that consumers have grown accustomed to with conventional lamps? How successful has LED technology been in adapting to fit old paradigms?

\section{A Lamps}

Although there were a few concerning products, the lumen output of the tested A lamps generally matched the claimed value and was mostly on target with equivalency claims. Further, all but one of the products exceeded the 2014 ENERGY STAR efficacy criterion, and the top product exceeded $100 \mathrm{~lm} / \mathrm{W}$-not to mention the six other products that exceeded $80 \mathrm{~lm} / \mathrm{W}$. This easily bests the efficacy of CFLs, and offers substantial energy

\footnotetext{
${ }^{11}$ The shape of A lamps is defined in ANSI C78.20-2003. A19 is the standard shape for $40 \mathrm{~W}$ and $60 \mathrm{~W}$ incandescent lamps with a medium screw base, whereas higher wattage lamps may be either A19 or A21. One lamp exceeded the ANSI A19 maximum length by $1 \%$, but this was considered within measurement error.

${ }^{12}$ CALiPER Report 20.1, Subjective Evaluation of Beam Quality, Shadow Quality, and Color Quality for LED PAR38 lamps, is available at: http://apps1.eere.energy.gov/buildings/publications/pdfs/ssl/caliper_20.1_par38.pdf
} 
savings compared to halogen and incandescent lamps-including halogen lamps that meet the Energy Independence and Security Act of 2007 (EISA) requirements now in effect. Output and efficacy of all the A lamps tested for RRL3 is shown in Figure 7, along with data from several other sources.

One interesting issue going forward will be the branding of different categories of lamp (e.g., $40 \mathrm{~W}$ equivalent, $60 \mathrm{~W}$ equivalent, etc.). With incandescent lamps now out of production, such equivalency claims will eventually become obsolete. Unless consumers become familiar with lumen output-consumer education efforts have been ongoing for some time-a different system may be needed. For this report, incandescent equivalent wattage numbers are still used.

In the $60 \mathrm{~W}$ equivalency claim category, CALiPER tested 15 products. All lamps except one (13RT-08) produced at least $90 \%$ of the claimed lumen output, although two produced more than $110 \%$ of the claimed value. Three produced less than the 800 lumens required by ENERGY STAR - a threshold that is also used by CALiPER and that

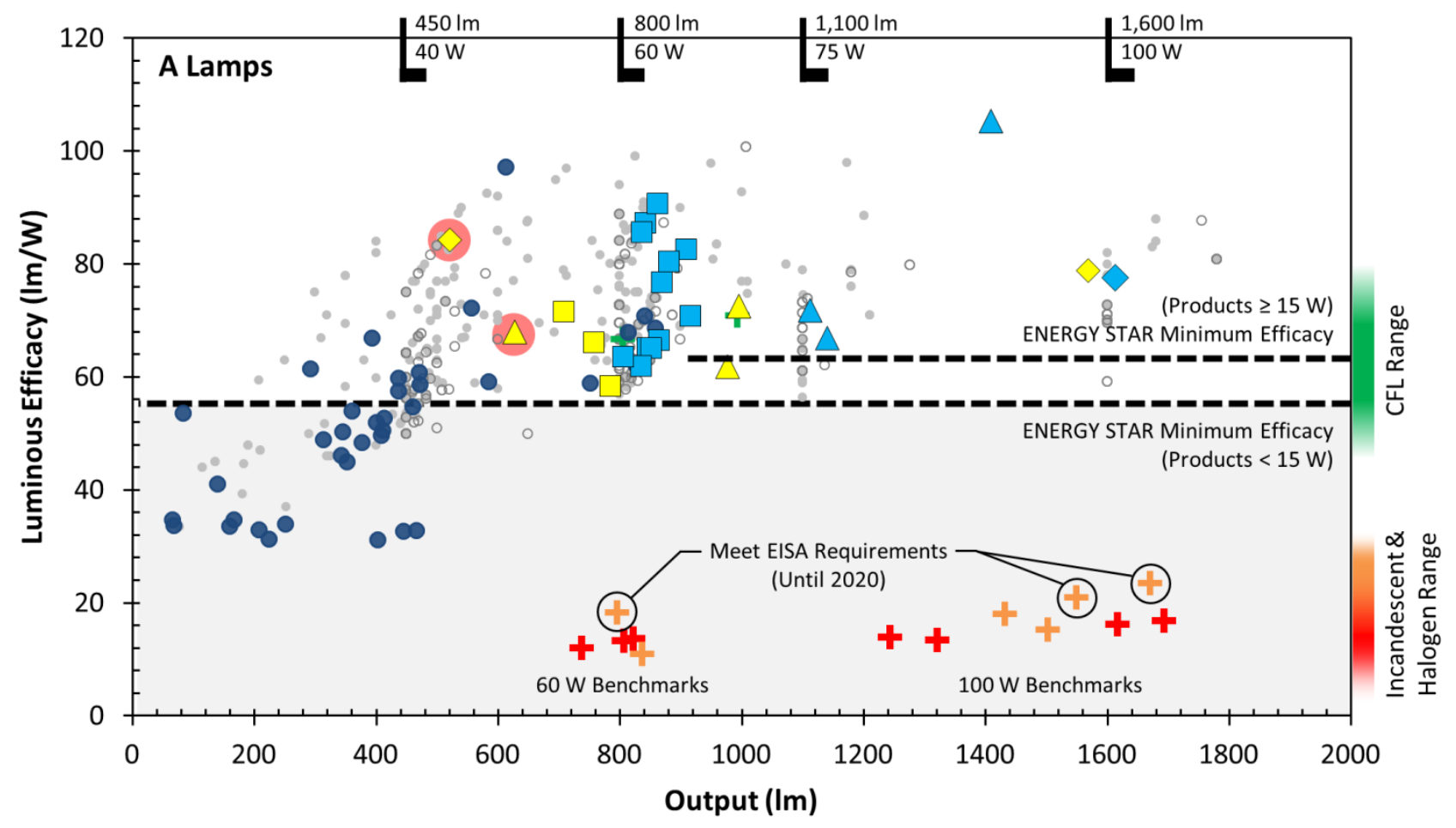

Retail Lamps Study 3 (2013)

$800 \mathrm{~lm} / 60 \mathrm{~W}$ Incandescent Category

$\triangle 1,100 \mathrm{~lm} / 75 \mathrm{~W}$ Incandescent Category

$1,600 \mathrm{~lm} / 100 \mathrm{~W}$ Incandescent Category

Met lumen equivalency threshold

Did not meet lumen equivalency threshold

Inappropriate equivalency claim
- Other CALiPER Tests (2007-2011) $)^{1}$

- LED Lighting Facts Data (January 2014)2

O ENERGY STAR Data (January 2014)²

+ Incandescent Benchmarks

+ Halogen Benchmarks

+ CFL Benchmarks

1. Includes RRL1 and RRL2.

2. Date of download; individual products older.

Figure 7. Lumen output and efficacy for the RRL3 A lamps and other datasets. Several of the RRL3 lamps did not meet the thresholds that are typically used for equivalency to incandescent $A$ lamps, shown at the top. 
is common throughout the lighting industry. However, only one was more than $5 \%$ below the threshold, and that product also emitted less than $90 \%$ of its claimed output. All the lamps exceeded the ENERGY STAR efficacy criterion, and the average for the group was $73 \mathrm{~lm} / \mathrm{W}$, with a maximum of $91 \mathrm{~lm} / \mathrm{W}$.

Based on historical trends, however, the greater accomplishment may be that all 15 lamps were relatively effective at reproducing the omnidirectional distribution characteristic of an incandescent lamp. Figure 8 shows a plot of luminous intensity versus vertical angle. ${ }^{13}$ Three of the LED products (RT13-08, RT13-11, and RT13-01) produced slightly less intensity at middle-to-high vertical angles (slightly above horizontal for a lamp with the base up), and one product (13RT-04) also product slightly higher intensity-relatively-at higher angles than the incandescent benchmark. Notably, these four products are on par with the halogen and CFL benchmarks, which also did not perfectly replicate the distribution of the incandescent benchmark. This performance of the $43 \mathrm{~W}$ halogen benchmark is particularly interesting; although it looks identical to a conventional $60 \mathrm{~W}$ incandescent lamp, the distribution is not the same, with a noticeable drop in intensity at nadir (straight down with the lamp base up).

It should be reiterated that a criterion for inclusion in the $60 \mathrm{~W}$-equivalent test category was a claim of an omnidirectional distribution, so it is not surprising that most of the distributions were very good. The level of consistency among the LED products, however, is noteworthy. If a more random sampling of products claiming equivalency to a $60 \mathrm{~W}$ incandescent lamp were undertaken, the diversity of luminous intensity distributions would have been greater, with the inclusion of many semi-directional lamps-which are often available at a lower cost than their omnidirectional counterparts. This trend is apparent with the $75 \mathrm{~W}$ - and $100 \mathrm{~W}$ equivalency claim lamps, as shown in Figure 9. Three of those eight products had a semi-directional emission,

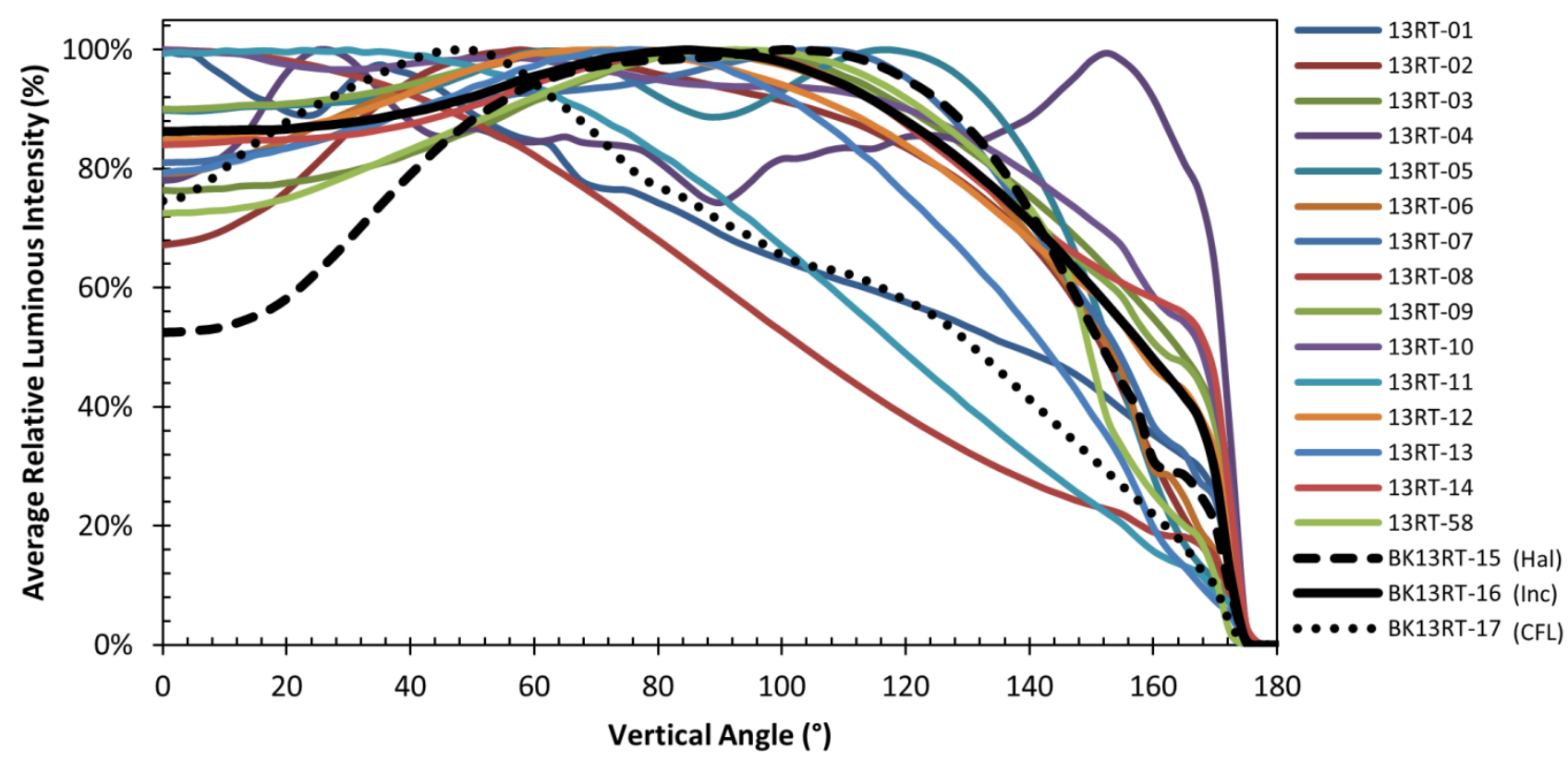

Figure 8. Average, relative luminous intensity at a vertical angle for the RRL3 LED A lamps in the $60 \mathrm{~W}$-equivalence category compared to incandescent, halogen, and CFL benchmarks. Many of the LED lamps had a distribution more similar to an incandescent lamp than the halogen or CFL lamps. A perfectly omnidirectional lamp would be represented by a horizontal line.

\footnotetext{
${ }^{13}$ This plot uses the same data as the more familiar polar plot, but relies on a rectangular coordinate system for easier comparisons.
} 


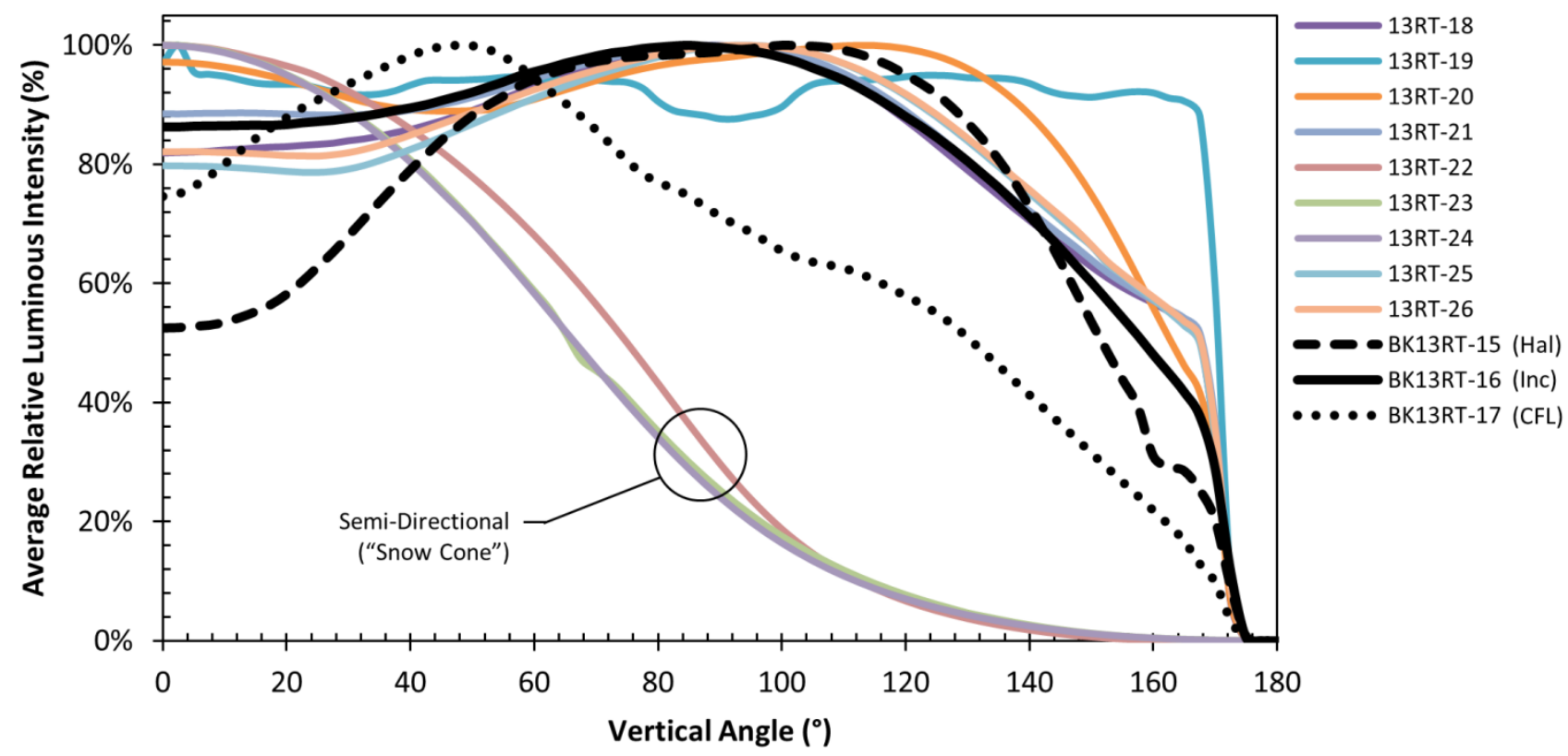

Figure 9. Average, relative luminous intensity at a vertical angle for the RRL3 LED A lamps in the $75 \mathrm{~W}$ - and $100 \mathrm{~W}$-equivalence categories compared to incandescent, halogen, and CFL benchmarks. The benchmarks are all in the 800-lumen (60 W) category, but this relative intensity plot allows for comparison. Some of the LED lamps had a distribution more similar to an incandescent lamp than the halogen or CFL lamps, but at least three lamps would be better classified as semi-directional because they emit little light toward the base end of the lamp. A perfectly omnidirectional lamp would be represented by a horizontal line.

emitting little light at high angles (towards the base of the lamp). Those three lamps would not be considered equivalent to a conventional incandescent lamp, regardless of lumen output or any other characteristic; this does not mean that they are not appropriate for any application, however.

Besides having many fewer available products, the $75 \mathrm{~W}$ - and $100 \mathrm{~W}$-equivalence categories also included a higher percentage of products that did not meet their equivalency claim. Rather than performance metrics dramatically different from the listed value, however, the equivalency claims were simply incorrect for products RT13-24 and RT13-22 - these products are highlighted red in Figure 7. While RT13-24 was one of two products in this combined group to produce less than $90 \%$ of its claimed lumen output, even at the full value it would not qualify as even a $60 \mathrm{~W}$ equivalent according to ENERGY STAR-the same situation as for RT13-22. Such erroneous claims present a significant peril for unsuspecting shoppers. Three of the other products in this group emitted slightly fewer than the 1,100 or 1,600 lumens required based on their claim, although the small differences are unlikely to be noticeable to a typical consumer.

Despite the two severely deficient products and three products with slightly low lumen output, the eight products in these two combined categories-though from only six manufacturers-represent a substantial step forward since RRL2. They also include one product (RT13-19) that was tested at $105 \mathrm{~lm} / \mathrm{W}$, which is substantially higher than its own claim and the highest efficacy for any medium-screw-base lamp tested by CALiPER to date. With a mean efficacy of $76 \mathrm{~lm} / \mathrm{W}$ for the group, it is encouraging that there are multiple energy-efficient choices for consumers looking to replace $75 \mathrm{~W}$ and $100 \mathrm{~W}$ incandescent lamps. 


\section{PAR30 Lamps}

While there was a plethora of 800-lumen LED A lamps, few exceeded 1,000 Im. A similar trend existed for PAR30 lamps, a group of which was selected in search of equivalents to $75 \mathrm{~W}$ halogen PAR30 lamps. These lamps, with claimed lumen output between 740 and $900 \mathrm{~lm}$, had the highest output of the 63 PAR30 lamps noted in the CALiPER survey of retail-available PAR30 lamps. Seven of the nine selected lamps claimed equivalence to $75 \mathrm{~W}$ halogen PAR30 lamps, with one claiming equivalence to a $60 \mathrm{~W}$ halogen PAR30 lamp and one to a $90 \mathrm{~W}$ halogen lamp. Conventional $75 \mathrm{~W}$ halogen PAR30 lamps-the highest wattage typically available in that form factorusually range between 900 and 1,100 $\mathrm{lm}$. Although specifiers typically consider center beam intensity, consumers are more likely to focus simply on wattage and total output.

With a range of 660 to $959 \mathrm{~lm}$ (as tested), the RRL3 LED PAR30s were generally slightly lower in output than the halogen PAR30 benchmarks that were also tested. With an average of $61 \mathrm{~lm} / \mathrm{W}$, however, they were much more energy efficient. Further, all of the lamps met the ENERGY STAR efficacy criterion, as shown in Figure 10. Also important to note is that ENERGY STAR does not distinguish between sizes of PAR lamps in its database, so ENERGY STAR data is not included in Figure 10, since the inclusion of higher wattage PAR38 lamps might

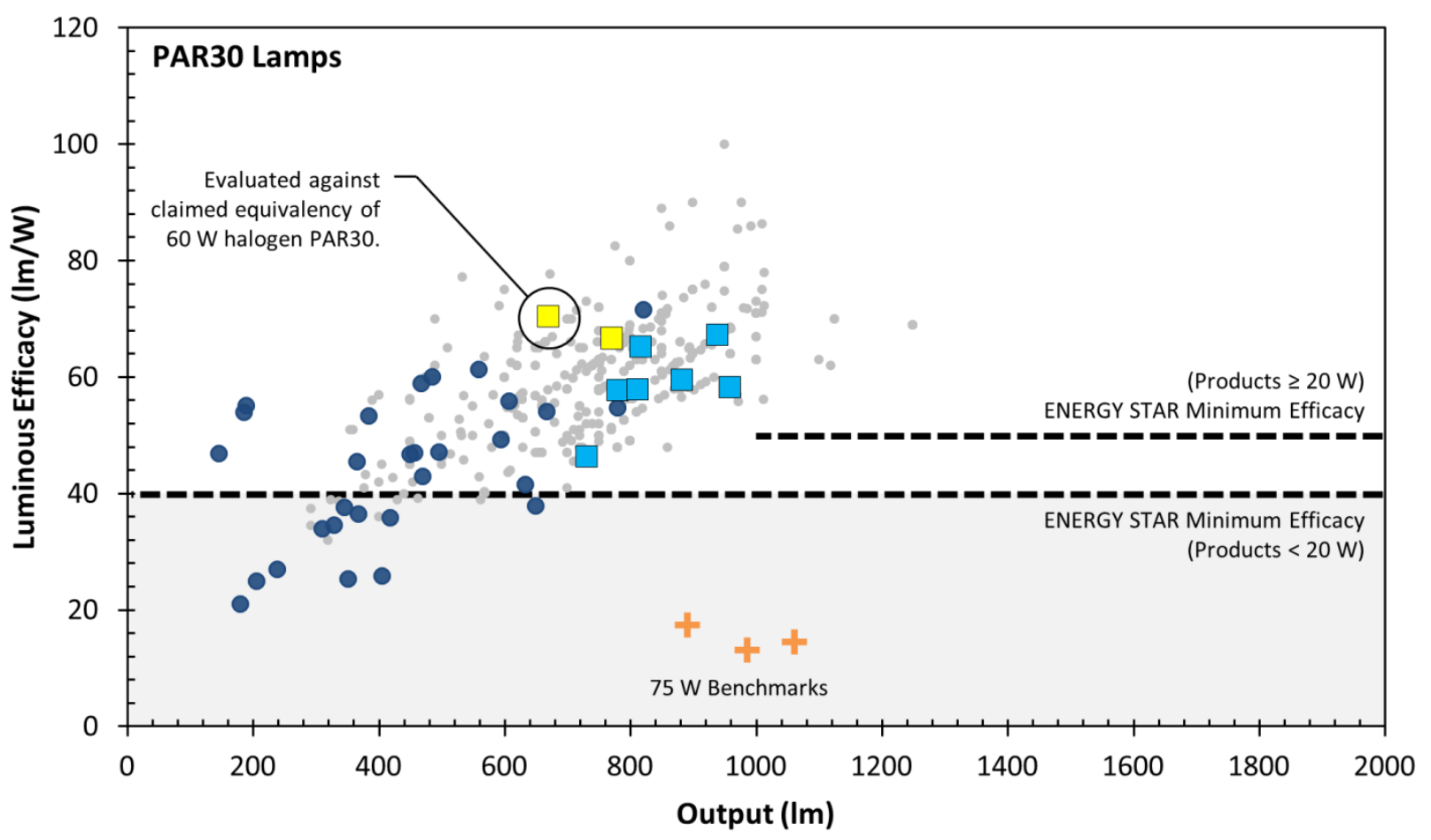

\begin{tabular}{|c|c|}
\hline Retail Lamps Study 3 (2013) & Other CALiPER Tests $(2007-2011)^{1}$ \\
\hline$\square$ Met CBCP equivalency threshold & - LED Lighting Facts Data (January 2014)² \\
\hline$\square$ Did not meet CBCP equivalency threshold & + Halogen Benchmarks \\
\hline
\end{tabular}

Figure 10. Lumen output and efficacy for the RRL3 PAR30 lamps and other datasets. Two of the RRL3 lamps did not meet the center beam intensity (CBCP) thresholds required for their equivalency claim and beam angle. One product in the group claimed equivalence to a $60 \mathrm{~W}$ PAR30 lamp rather than a $75 \mathrm{~W}$ lamp, and it was evaluated accordingly. ENERGY STAR does not distinguish between PAR30 and PAR38 lamps, so that data set has been omitted. 
misrepresent the state of retail-available PAR30 lamps. The data for LED Lighting Facts, which does allow for separation of PAR30 lamps, shows similar maximum performance as the CALiPER test results. This level is appropriate given that halogen PAR30 lamps have traditionally only been available up to $75 \mathrm{~W}$, or approximately $1,000 \mathrm{~lm}$.

For equivalency evaluation, ENERGY STAR relies on center beam intensity, in combination with beam angle and the claimed equivalent wattage. Using the ENERGY STAR tool, ${ }^{14}$ seven of the nine RRL3 LED PAR30 lamps met their claim, ${ }^{15}$ although the tool allows for a two-sigma deviation below the predicted value-a wide margin. Notably, only three of the retail-available PAR30 lamps provided a beam angle in retailer data-although seven listed the beam angle on the manufacturer's specification sheet-with two additional lamps carrying a flood designation. This lack of characterization of the luminous intensity distribution by retailers and/or product packaging could make choosing an appropriate product more difficult for consumers.

Average luminous intensity across all horizontal angles at each vertical angle is shown in Figure 11. In contrast with Figures 8 and 9 (luminous intensity distribution for the RRL3 A lamps), Figure 11 shows actual intensity, rather than relative intensity. Eight of the PAR lamps had luminous intensity distributions within the range of the three benchmark products tested by CALiPER. As previously noted, however, it may be difficult for consumers to distinguish among them, and, in fact, performance was somewhat different, with beam angles between $23^{\circ}$ and $38^{\circ}$. One product (13RT-34) was not within the range of the benchmark, having a beam angle of $110^{\circ}$. This product would more appropriately be categorized as an R30 lamp instead of a PAR30 lamp. This same product

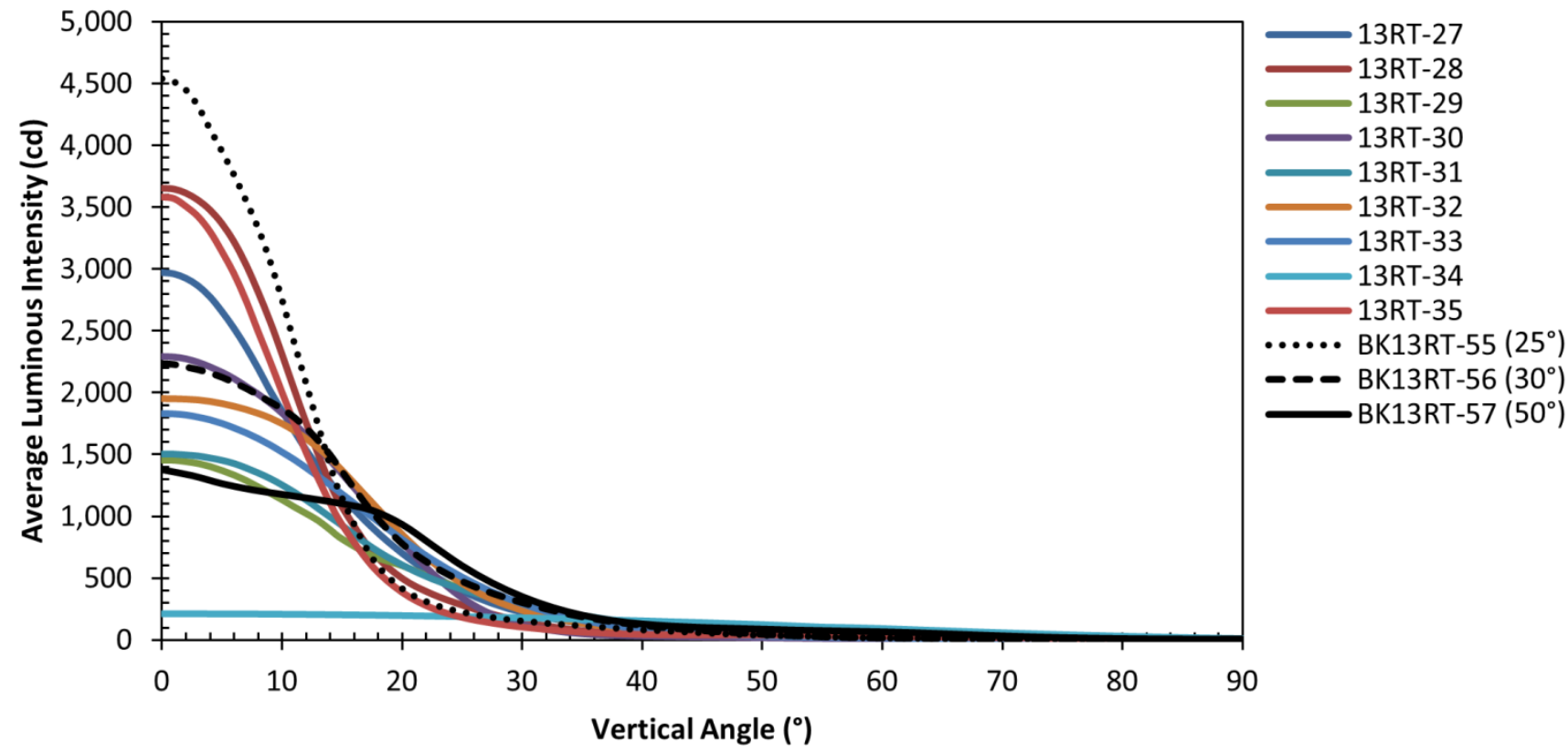

Figure 11. Average luminous intensity across all horizontal angles, at each vertical angle for the RRL3 PAR30 lamps and benchmark halogen products. In general, the products had similar distributions compared to the benchmark products, and the CBCP was not substantially different from the benchmark with a similar beam angle. The exceptions were 13RT-34, which was incorrectly labeled a PAR30 lamp, and 13RT-29, which performed closer to a $50^{\circ}$ lamp than its $32^{\circ}$ measured beam angle would suggest.

\footnotetext{
${ }^{14}$ The ENERGY STAR directional lamp equivalency tool is available at: http://www.energystar.gov/LampsCBCP

${ }^{15}$ The product claiming equivalence to a $90 \mathrm{~W}$ halogen PAR30 lamp was evaluated using the tool's maximum of $75 \mathrm{~W}$ for a halogen PAR30 lamp.
} 
was the only one in the PAR30 group with lumen output and efficacy less than $90 \%$ of its claimed value, and it did not meet its equivalency claim according to ENERGY STAR.

\section{MR16 Lamps}

Unlike the A lamps tested for RRL3, many of the MR16 lamps tested performed worse than claimed. Six of 11 products that made an equivalency claim - there were 13 total MR16s tested, but two did not make an equivalency claim - failed to meet that claim, according to ENERGY STAR criteria. Additionally, three productsincluding two that failed to meet the equivalency claim and one that did not make a claim-produced less than $90 \%$ of the claimed lumen output. One product (13RT-45) emitted less than half of the claimed lumen output. Another product (13RT-57) had a measured beam angle over $100^{\circ}$, which is not similar to halogen MR16 lamps, as shown in Figure 12; this product should not be called an MR16.

Beyond many inaccurate claims, both Figure 12 and Figure 13 show that the LED MR16s rarely stacked up against halogen MR16 benchmarks. No LED MR16 lamp tested matched the lumen output of its claimed halogen equivalent, and many were more than 25\% lower. Data from LED Lighting Facts and ENERGY STAR indicates that this performance level is not only an attribute of LED MR16 lamps sold at retail stores, but of the broader LED MR16 market. Further, at the same beam angle LED MR16 lamps simply do not match the center beam intensity of $50 \mathrm{~W}, 12 \mathrm{~V}$ halogen MR16s, and only a few can match the performance of $35 \mathrm{~W}, 12 \mathrm{~V}$ halogen MR16s. Those that meet their claims according to ENERGY STAR tend to have a smaller beam angle than their nominal valuewhich is used in determining equivalency-and also rely on the substantial leeway granted by ENERGY STAR. As a whole, the performance of the LED lamps, along with their equivalency claims, is closer to that of $120 \mathrm{~V}$ halogen MR16 lamps, but it is inappropriate to compare the two different base types; they are not interchangeable and tend to be used in very different applications.

As a whole, the MR16s averaged $363 \mathrm{~lm}, 6.5 \mathrm{~W}$, and $57 \mathrm{~lm} / \mathrm{W}$, with a substantial range in performance.

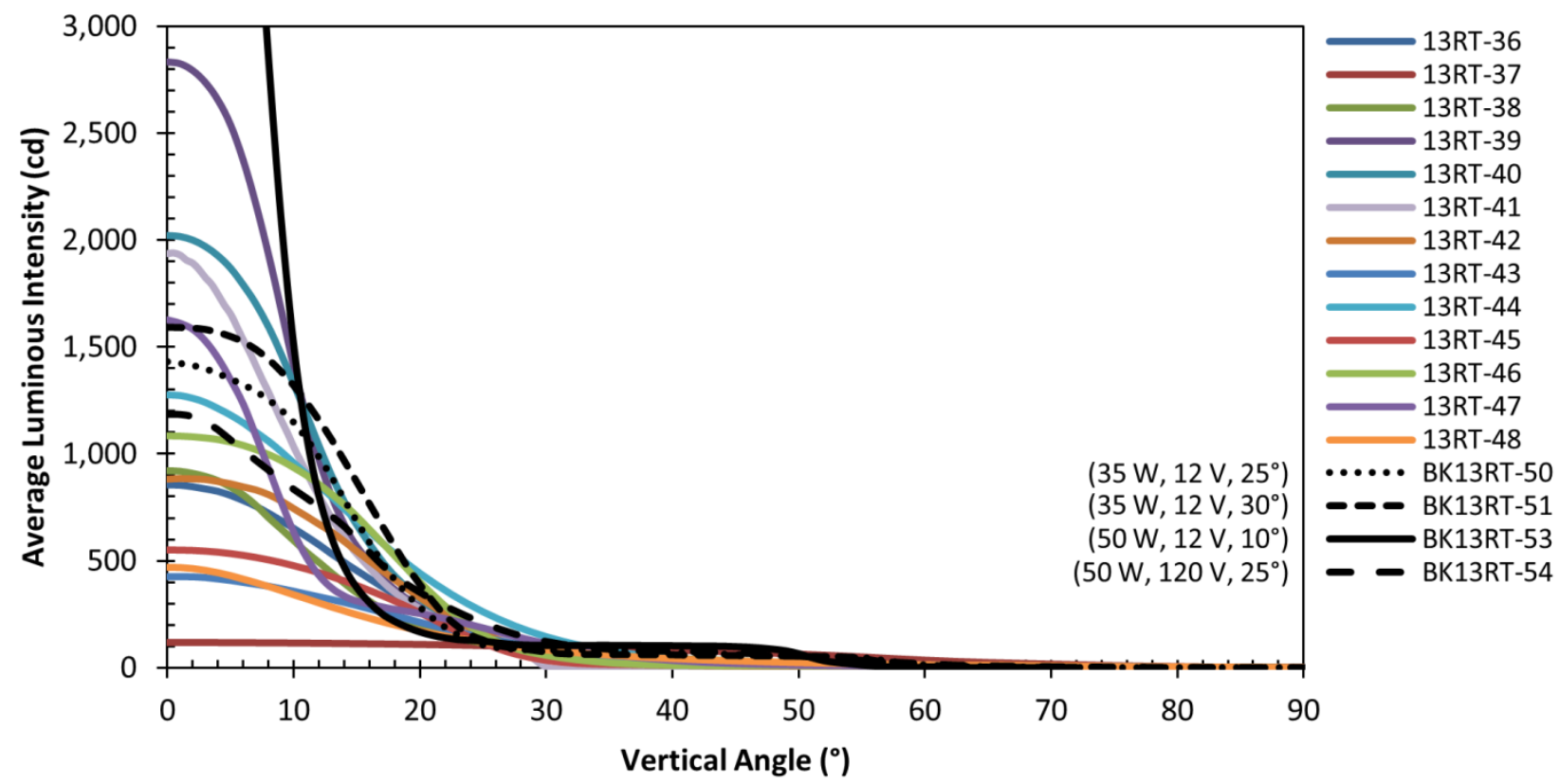

Figure 12. Average luminous intensity across all horizontal angles for the RRL3 MR16 lamps and benchmark halogen products. Many of the LED products did not provide comparable CBCP to the halogen benchmark at the appropriate wattage and beam angle. At least one product, 13RT-45, did not have an appropriate distribution for an MR16 lamp. The $10^{\circ}$ halogen lamp had a measured CBCP of 8,909 cd (not shown). 


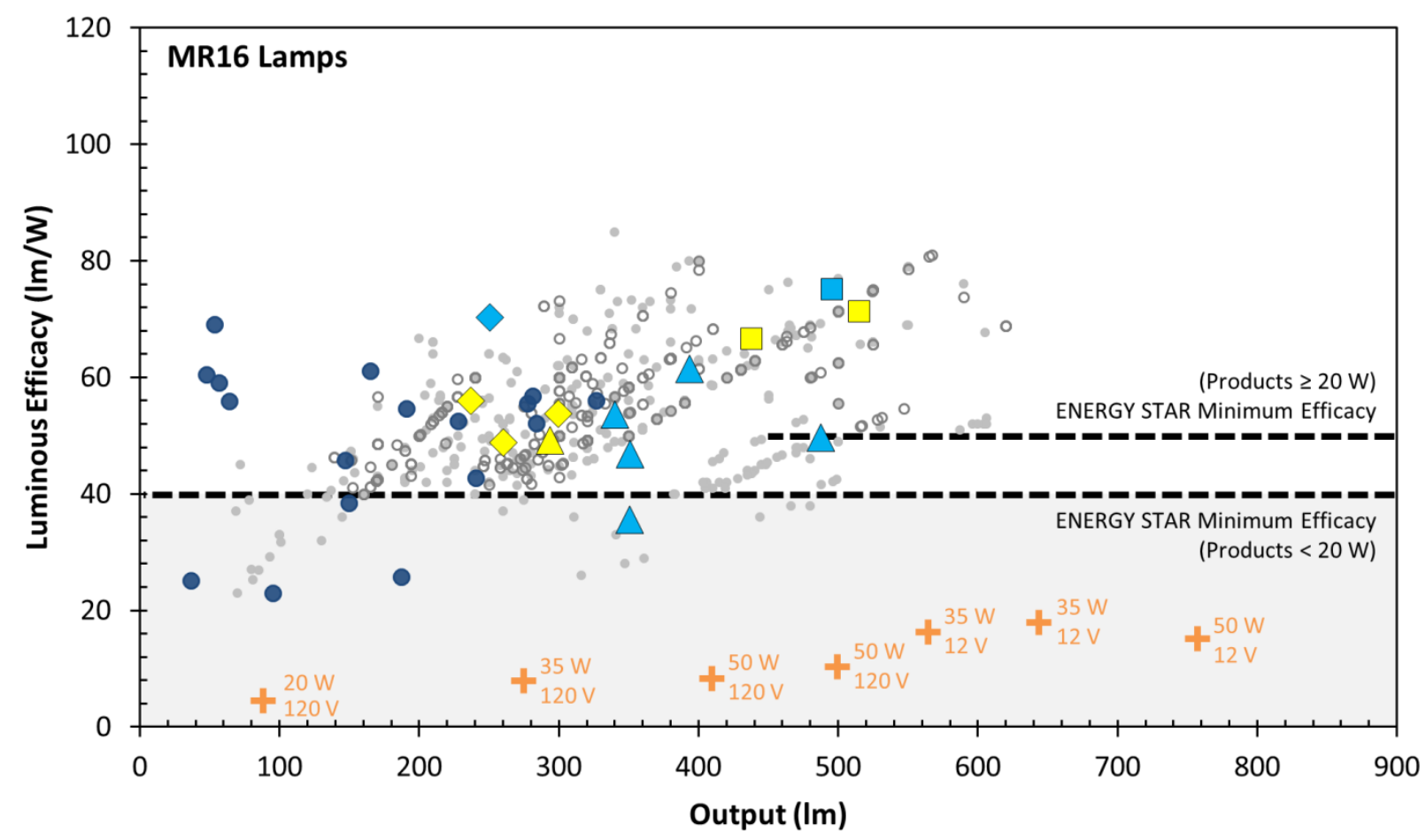

\section{Retail Lamps Study 3 (2013)}

$\square 0$ W, GU5.3 Halogen Category

$\triangle 35$ W, GU5.3 Halogen Category

$\diamond 50 \mathrm{~W}, \mathrm{GU10}$ Halogen Category

Met CBCP equivalency threshold

Did not meet CBCP equivalency threshold
- Other CALiPER Tests (2007-2011) 1

- LED Lighting Facts Data (January 2014)2

O ENERGY STAR Data (January 2014) ${ }^{2}$

+ Halogen Benchmarks

1. Includes RRL1 and RRL2.

2. Date of download; individual products older.

Figure 13. Lumen output and efficacy for the RRL3 MR16 lamps and other datasets. Many of the RRL3 lamps did not meet the CBCP thresholds required for their equivalency claim and beam angle.

However, it is important to consider the performance of each of the three classes of product considered ("35 W" GU5.3, "50 W" GU5.3, and "50 W" GU10) separately. The 35 W GU5.3 group had mean output of $369 \mathrm{~lm}$ (minimum $294 \mathrm{~lm}$ to maximum of $488 \mathrm{~lm}$ ) at an average efficacy of $49 \mathrm{~lm} / \mathrm{W}$. On average, they drew $7.6 \mathrm{~W}$. In contrast, the $50 \mathrm{~W}$ GU5.3 group emitted an average of $483 \mathrm{~lm}$ (minimum of 438 to maximum of 515) at an average efficacy of $71 \mathrm{~lm} / \mathrm{W}$. Surprisingly, they drew an average of $6.8 \mathrm{~W}$, lower than the group with a lower equivalency claim. This illustrates an important point: a higher wattage LED product does not necessarily emit more lumens, in contrast with the incandescent lamps with which consumers are familiar. Notably, the number of products within each group is relatively small, and the trend is not universal. The final group included in this study, 50 W GU10, emitted an average of $262 \mathrm{~lm}$ at an efficacy of $57 \mathrm{~lm} / \mathrm{W}$. Like their halogen counterparts, the performance of the $120 \mathrm{~V}$ lamps (GU10) - which are generally a retail-specific product type-was substantially lower.

Undoubtedly, the MR16 form factor is one of the most difficult for LED lamps, which require mass and volume for thermal management. The small size often requires tradeoffs and compromises, given the state of the 
technology today. As LED package efficacy improves, it may be possible to avoid some of the pitfalls of many of today's LED MR16 lamps (e.g., flicker). Such improvements will be welcomed throughout the industry.

\section{Color Characteristics}

Perhaps as much as any other characteristic, consumers react strongly to color quality. This is evidenced by CFLs sometimes being branded as the "green light" and LED sometimes being given the moniker of "blue light." Especially for LEDs, this is a bad generalization, since the output can be tuned to almost any chromaticity. Nonetheless, the stigma has some bearing, as some early medium-screw-base LED lamps had higher CCTs than conventional incandescent and halogen lamps, which may have surprised uninformed consumers. Some higherCCT LED products are still available, but they are now usually clearly labelled and fall within a product line that also includes lower-CCT products, giving consumers a clear choice.

While some consumers have become familiar with the CCT scale, the knowledge is not universal. As a result, retailers and manufacturers continue to use descriptors of appearance to describe their products.

Unfortunately, there is no standard language, resulting in myriad descriptors that can be unclear and confusing. These include "warm white," "soft white," "bright white," "daylight white," "cool white," "crisp white," "neutral white," and probably others. On top of this, there is divergence on offering $2700 \mathrm{~K}$ or $3000 \mathrm{~K}$ (nominal) products, with most manufacturers offering one or the other, and some offering both. In many cases, these two nominal CCTs bracket the typical CCT for halogen and incandescent lamps, which CALiPER benchmark tests put between $2514 \mathrm{~K}$ and $3079 \mathrm{~K}$. Most of the higher-CCT products available at retail stores have settled on $5000 \mathrm{~K}$.

All of the RRL3 lamps except two, which were both above $5500 \mathrm{~K}$, had a nominal CCT of either $2700 \mathrm{~K}$ or $3000 \mathrm{~K}$, as shown in Figure 14. While it was CALiPER preference to purchase products in this range to aid comparison, the small number of higher-CCT products is also reflected in the total survey of available products, where approximately $15 \%$ were noted as having a CCT of $3500 \mathrm{~K}$ or greater. For this report, both of the higher-CCT products chosen were MR16 GU10 lamps. The average CCT for all the other groups of lamps was between 2822 K (75 W A lamps) and 3038 K (50 W MR16 GU5.3 lamps). Notably, the MR16s included only one product at 2700 $\mathrm{K}$, and the PAR30s only two, while slightly more A lamps were $2700 \mathrm{~K}$ than $3000 \mathrm{~K}$. The product types are not differentiated in Figure 14.

Another important aspect of color appearance is $D_{u v}$. Only one product (13RT-34) had a $D_{u v}$ exceeding the tolerances for white light established in ANSI C78.377-2011 ${ }^{16}$ - the maximum $D_{\mathrm{uv}}$ for the three samples was -0.0083. More importantly, however, is that a vast majority $(80 \%)$ of the products had an average $D_{u v}$ less than zero, ${ }^{17}$ as shown in Figure 15. Historically, only $49 \%$ of CALiPER-tested products and $30 \%$ of the A, PAR30, and MR16 lamps listed by LED Lighting Facts $-D_{u v}$ is reported for about $28 \%$ of the products, as it is not a required metric-have had that characteristic. This is a noteworthy outcome because several recent research studies have indicated preference for negative $D_{u v} s$, which correspond to white light with a slightly pink appearance rather than a slightly green appearance.

Color rendering is generally quantified using CRI, as shown in Figure 14. As is illustrated, all but three of the LED lamps tested for RRL3 (13RT-13 [79], 13RT-22 [52], 13RT-45 [73]) met the ENERGY STAR minimum CRI criterion of 80 . In contrast, three products had a CRI greater than 90 (13RT-58, 13RT-27, 13RT-42). A vast majority of

\footnotetext{
${ }^{16}$ For nominal CCTs of $2700 \mathrm{~K}$ and $3000 \mathrm{~K}$, the allowable $\mathrm{D}_{\mathrm{uv}}$ range is \pm 0.006 .

${ }^{17}$ It is generally inappropriate to average $D_{\text {uv }}$ values because positive and negative values for the same product may be averaged to represent performance that is better than actual. The average was used in this case because seven products had at least one sample with a positive $D_{u v}$ and one sample with a negative $D_{u v}$.
} 


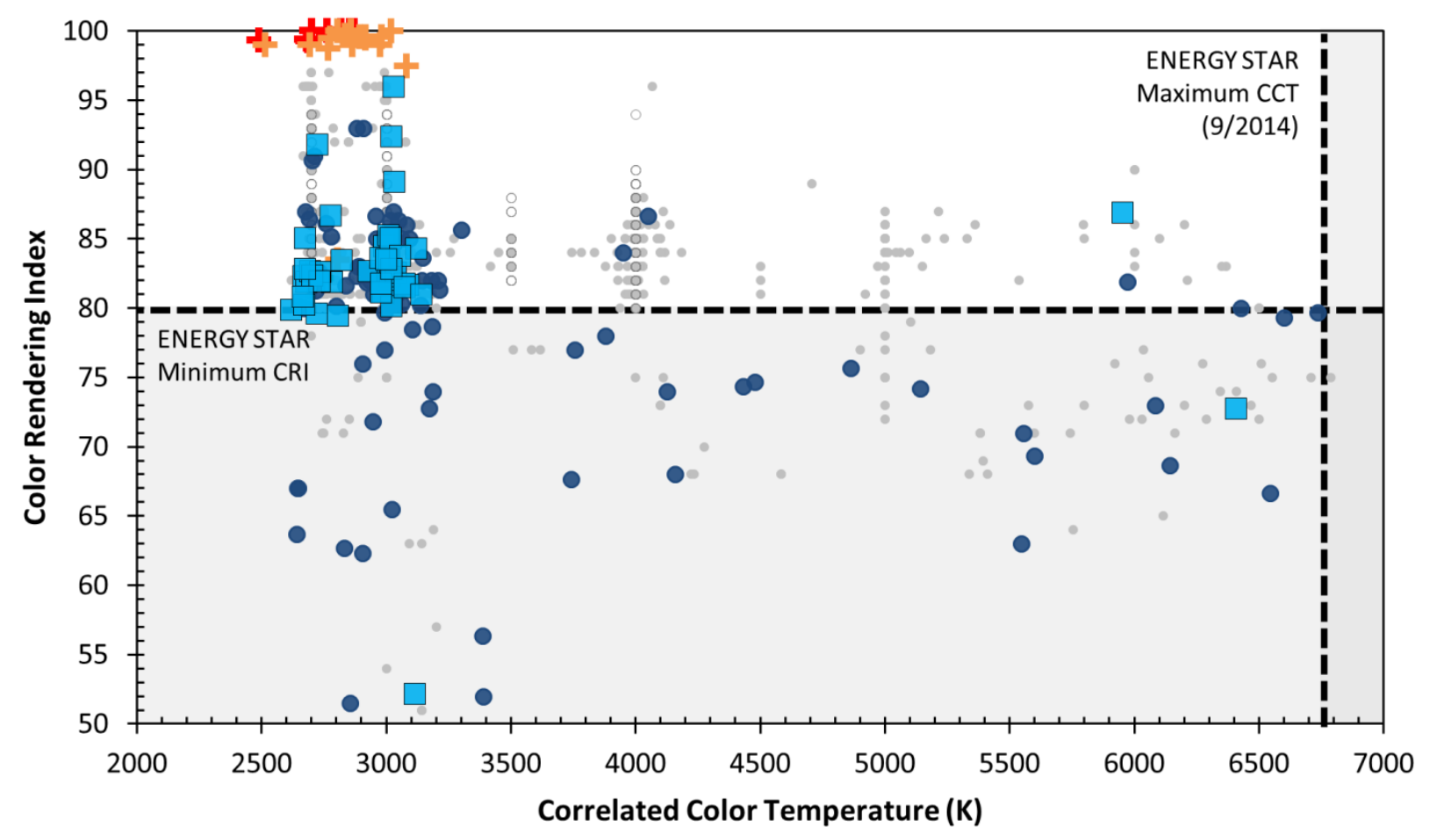

\begin{tabular}{ll}
\hline$\square$ Retail Lamps Study 3 (2011) & + Incandescent Benchmarks \\
Other CALiPER Tests (2007-2011) & + Halogen Benchmarks \\
LED Lighting Facts Data (January 2014) & + CFL Benchmarks \\
O ENERGY STAR Data (January 2014) & \\
\hline 1. Includes RRL1 and RRL2. & \\
2. Date of download; individual products older. &
\end{tabular}

Figure 14. CCT and CRI characteristics of the RRL3 lamps. A vast majority of the products purchased had a CCT between 2700 and 3100 $\mathrm{K}$, with a CRI in the low 80s. However, higher CCT products are also widely available-though they were often not purchased for this study. Higher- and lower-CRI products are also available.

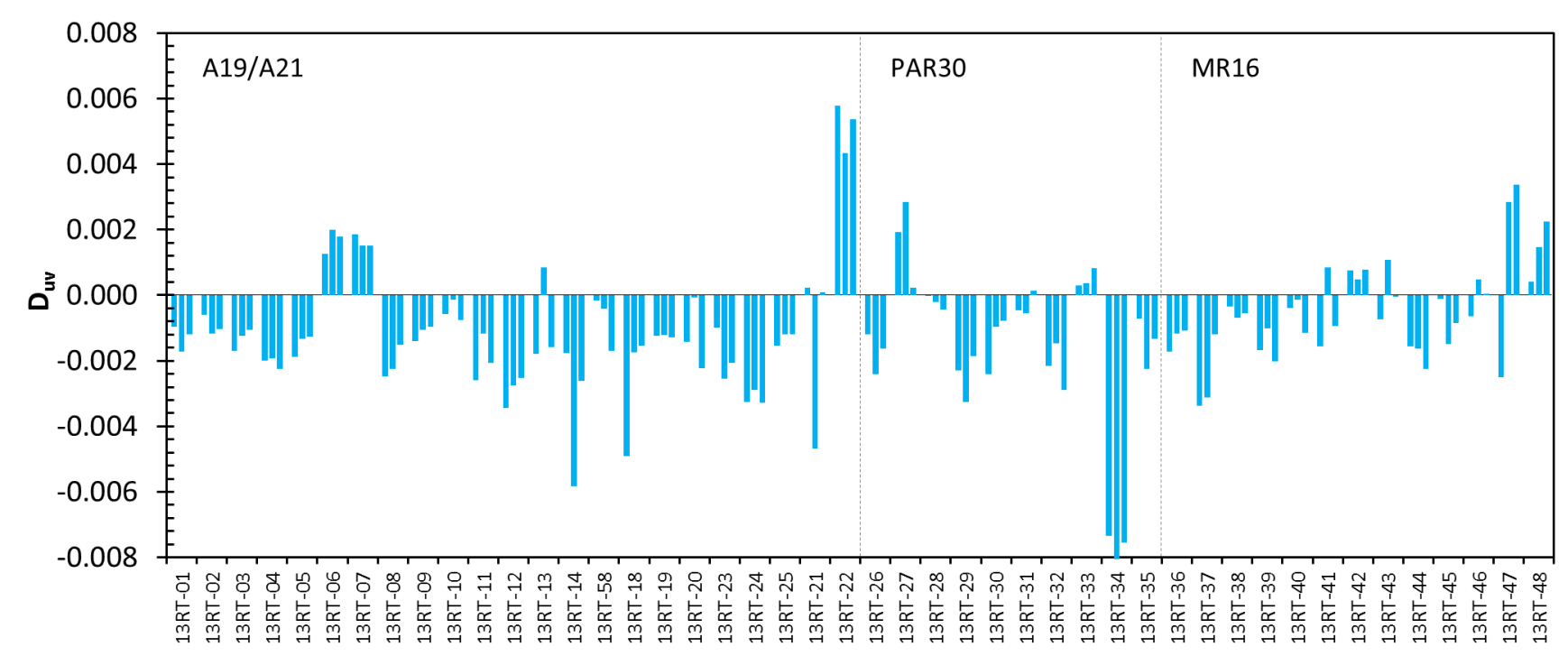

Figure 15. $D_{u v}$ values for each RRL3 lamp study. A vast majority of the lamps had a $D_{u v}$ less than zero. 
products had a CRI between 80 and 85 , which is also characteristic of the ENERGY STAR and LED Lighting Facts data for the same product types. Like many other attributes, this is in contrast with the results from earlier CALiPER studies on retail lamps, which showed many having CRIs less than 80 . For the two lamps that had a CRI substantially below 80 , no value was listed by the manufacturer or retailer; consumers should be cautious when purchasing such products. In this case, neither would have appropriate color quality for a residential interiorparticularly not 13RT-22.

Figure 16 further explores the color rendering quality of the RRL3 lamps-excluding the two lamps with a higher CCT-by using two metrics of the Color Quality Scale (CQS), which was developed by the National Institute of Standards and Technology (NIST). Although it has not been officially adopted by a standards organization and the values are not typically reported by manufacturers, CQS is used in this report to provide additional analysis. The two metrics shown in Figure $16 \mathrm{a}$ are $\mathrm{Q}_{\mathrm{f}}$ and $\mathrm{Q}_{\mathrm{g}}$. The former is a measure of color fidelity, or similarity to how an incandescent lamp would render colors: the higher the better. The latter is a measure of a source's gamut
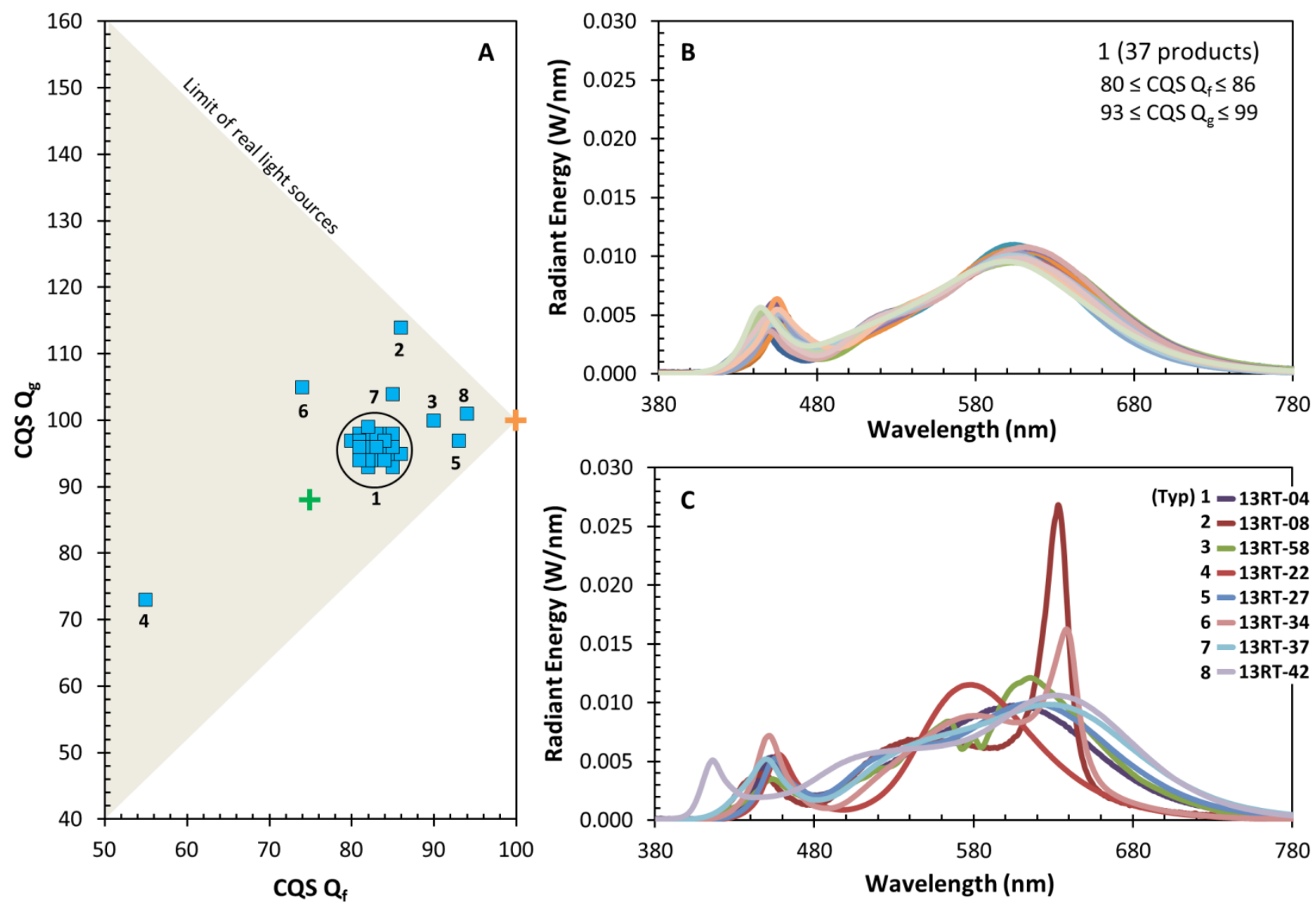

Figure 16. A: Plot of CQS $Q_{g}$ versus CQS $Q_{f}$. A higher value of $Q_{f}$ indicates more similarity to the reference source (approximately an incandescent lamp for these lamps). The two high-CCT products are not shown. A higher value for $\mathrm{Q}_{\mathrm{g}}$ indicates greater saturation. The labels correspond to the SPDs shown in Figures 16b and 16c.

B: SPDs for the 37 "standard" lamps plotted within the circle in Figure 16a.

C: SPDs for the seven lamps shown outside the circle in Figure 16a, as well as one SPD representing the typical performance of a lamp within the circle. 
area, which roughly correlates to how saturated or vivid a source will make colors appear-a higher $\mathrm{Q}_{\mathrm{g}}$ indicates greater saturation. More than $80 \%$ of the $2700 \mathrm{~K}$ and $3000 \mathrm{~K}$ products purchased for RRL3 had characteristics that were very similar; their spectral power distributions (SPDs), which are all nearly identical, are shown in Figure $16 \mathrm{~b} .{ }^{18}$ Figure $16 \mathrm{c}$ shows the SPDs for seven products that varied from the typical, as well as one SPD to represent the common type.

The products labeled 3, 5, and 8 all exhibited greater color fidelity than the other LED lamps, but did so by varying the SPD in very different ways. One product added a red diode to the package, another filtered out some of the yellow light, and the third used a violet pump instead of a blue pump combined with a broader-emitting phosphor. None of these approaches is necessarily superior, but the data illustrates the contrast between the growing uniformity of the "standard grade" LED products and the diversity of the "high color quality" products.

The products labelled 2 and 7 are notable because, on average, they increase the saturation of colors, despite having the same fidelity score as the bulk of the LED products in this study. In many cases, higher saturation is preferred. Plots of saturation are shown for the labelled products in Figure 17. As is evident, to achieve higher saturation, it is necessary to reduce fidelity; this is a fundamental concept of the two metrics.

The final two products with SPDs that deviated from the normal, labelled 4 and 6, are very different. Product 4 (13RT-22) had very poor color quality, as previously noted. Figure $16 \mathrm{c}$ shows that it has much less emission at longer wavelengths (red). In contrast, the product labelled 6 (13RT-34) had a CRI of 83, but a lower $\mathrm{Q}_{\mathrm{f}}$ of 74 . This product also used a red diode in the package-like RT13-08 (2)-but with a much different result. The lower
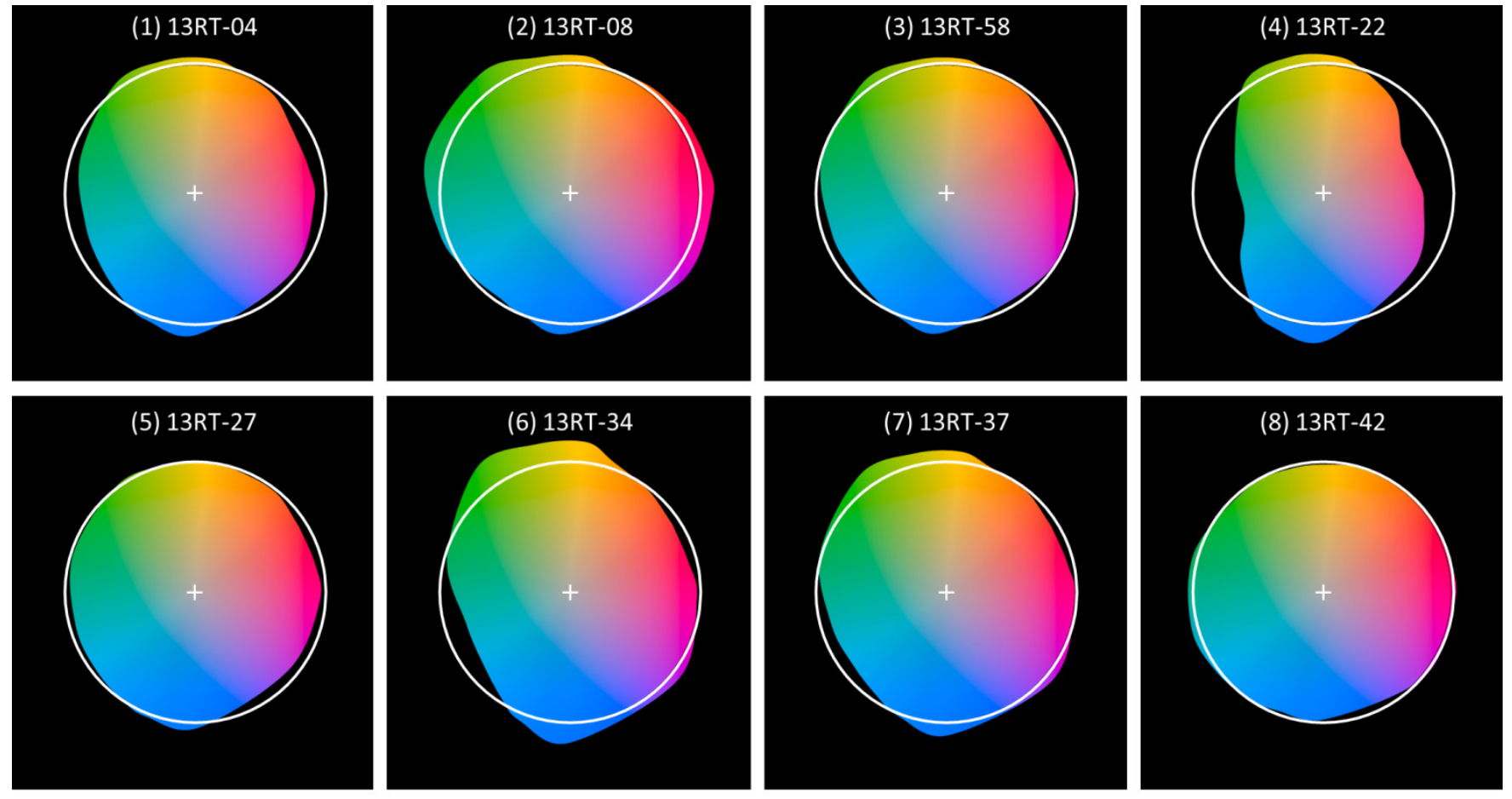

Figure 17. Saturation icons for the eight lamps documented in Figure 16c. The white circle represents the benchmark lamp (approximately an incandescent lamp). Increased saturation occurs where the color space exceeds the limits of the circle. Desaturation occurs where the colored space is inset from the white circle. Product 8 renders colors very similar to an incandescent lamp.

\footnotetext{
${ }^{18}$ For comparison purposes, the SPDs were normalized so that each would produce the same lumen output.
} 
fidelity score $\left(Q_{f}\right)$ and higher saturation score $\left(Q_{g}\right)$ occur because the product saturates reds and greens more than the comparison standard (approximately an incandescent lamp), which reduces its similarity to the reference. Despite the lower fidelity score, this product may actually be preferred. As with all of the SPDs noted, the purchaser will have to decide what is appropriate, which can be a daunting task for someone unfamiliar with color metrics.

\section{Electrical Characteristics}

Power factor versus input power is shown in Figure 18. Power factor is the metric that is used most frequently to describe power quality, although it is most important at a system level rather than at the individual product level. For instance, combining multiple loads can result in a power factor that is higher than for any of the parts. Nonetheless, most lighting specifications include power factor requirements. ENERGY STAR requires all products drawing $5 \mathrm{~W}$ or more to have a power factor greater than or equal to 0.70 .

Several RRL3 lamps had a power factor less than 0.70, all but one of which was an MR16 lamp. In fact, six of the 13 MR16 lamps tested for this report had a power factor less than 0.70 , including at least one product in all three subcategories. The other product with a power factor less than 0.70 was $13 R T-22$, an A lamp which had

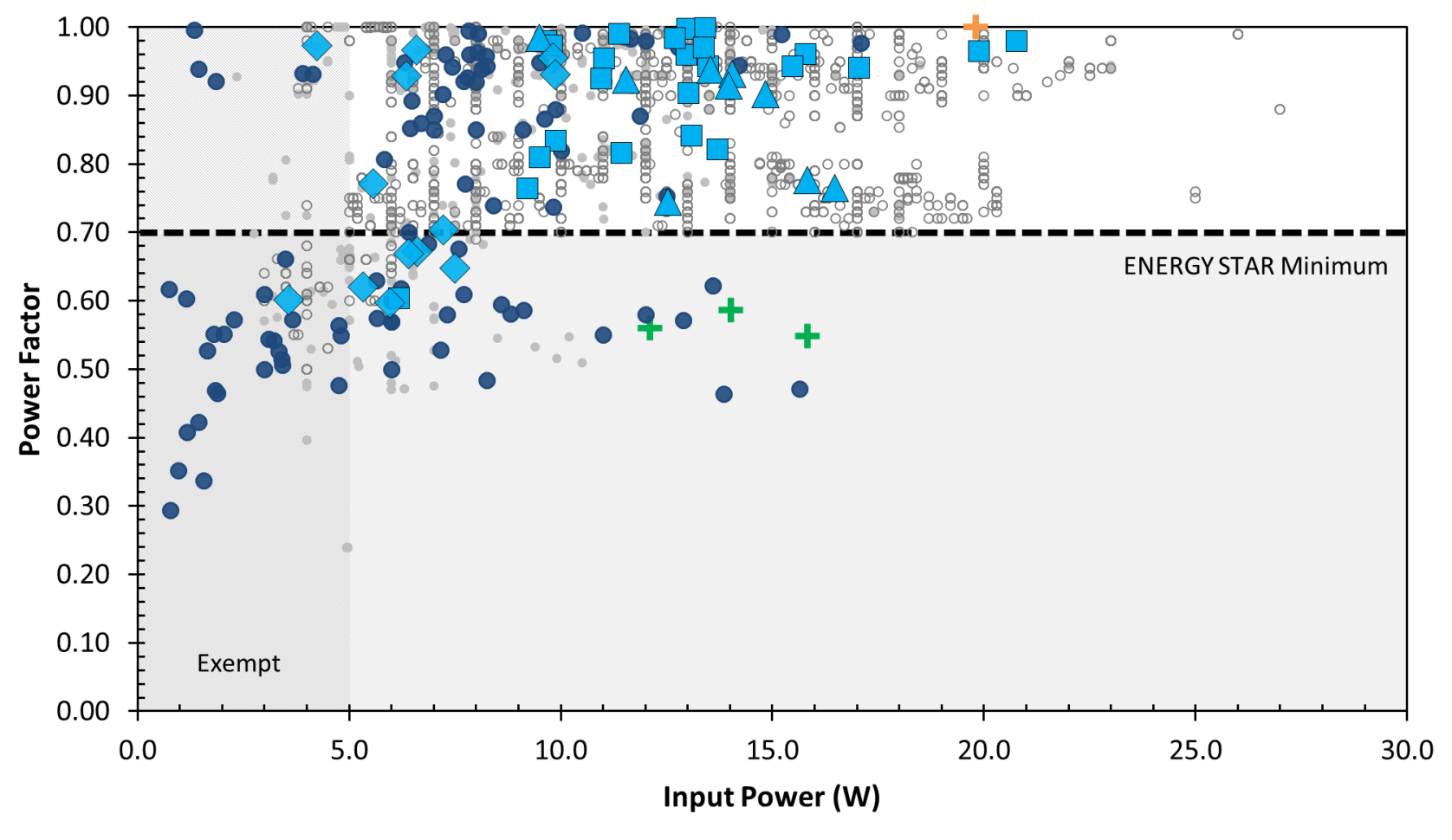

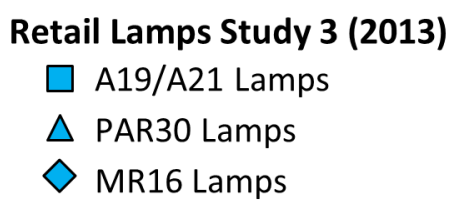

Retail Lamps Study 3 (2013)

$\square$ A19/A21 Lamps

MR16 Lamps
Other CALiPER Tests (2007-2011)
- LED Lighting Facts Data (January 2014)²
O ENERGY STAR Data (January 2014)²
+ Halogen Benchmarks
+ CFL Benchmarks

1. Includes RRL1 and RRL2.

2. Date of download; individual products older.

Figure 18. Power factor versus input power for the RRL3 lamps. Almost all of the lamps with a power factor less than 0.70 were MR16 lamps. 
poor performance in a number of other categories as well. All of the PAR30 lamps had a power factor above 0.70 .

On average, the RRL3 products are drawing much more power than the lamps from previous retail studies. From an energy use perspective, this seems counter to progress. However, the lamps provide substantially more light, and are much more effective in replacing $60 \mathrm{~W}$ or greater incandescent A lamps, for example. In general, increasing the performance of LED lamps provides more opportunity for them to be installed, which has the net effect of reduced energy use. As more and more key benchmarks (e.g., $60 \mathrm{~W}$ A lamps) are reached by LED lamps, increasing efficacy can be used to reduce input power, rather than increase lumen output.

All of the products were tested at their nominal rated voltage-either $120 \mathrm{~V}$ or $12 \mathrm{~V}$-based on the base type. The MR16 products with a GU5.3 (pin) base were tested at $12 \mathrm{~V}$, and all other products were tested at $120 \mathrm{~V}$. Notably, operating voltage was often not specified on retailer webpages, and sometimes not by the manufacturer either. For three MR16 products, the voltage listed on the retailer or manufacturer webpage was the opposite of what is customary for the given base type; these were determined to be erroneous listings and/or typographical errors.

Low-voltage LED MR16 lamps are often rated for either AC (alternating current) or DC (direct current) operation-or both-although in some cases, this was also not specified by the retailer or manufacturer. DC operation was explicitly specified for product RT13-41, so it was the only product tested using that configuration. Photometric testing using the DC configuration may produce more reliable results for those products operable under either AC or DC, but AC was chosen by default to replicate the likely installation in a residence.

\section{Cost}

Although the sample for this study was substantively different from the previous two CALiPER studies on retail lamps, it is still interesting to consider cost data. As shown in Figure 19, the general distribution of prices for RRL3 was similar to the previous two studies. This is despite the fact that most retailers now carry an LED A lamp in the $60 \mathrm{~W}$-equivalent category that is less than $\$ 10.00$, for example. Figure 19 , as with all price data in this report, only shows data for A, PAR30, and MR16 lamps, which are the three types that were evaluated in each study. Note that the sample sizes were different for each study $(20,28$, and 46 for RRL1, RRL2, and RRL3, respectively), so absolute differences in quantity within a given bin should be disregarded. Analyzing the mean price for each of the three studies reveals a reversal of the price drop between RRL1 and RRL2; the mean prices for RRL1, RRL2, and RRL3 were \$32.08, \$26.57, and \$30.09, respectively.

The critical aspect of these price comparisons is that the performance of the lamps is not equivalent. The selection criteria for RRL3 specifically focused on the highest output LED lamps available, which generally cost more. Table 7 illustrates average price structures for five product brands across different levels of $A$ lamp lumen output. The data was compiled using online prices recorded by CALiPER in August 2013. As with all pricing data, it is influenced by local and national utility rebates (or lack thereof) as well as local price variation, and has likely changed since the time of data collection. As shown, the price premium for higher lumen output does not follow a linear trend, nor does the price per kilolumen or price per lumen-per-watt. Thus, it can be challenging to compare the RRL3 lamps, which are generally the highest output LED lamps currently available of the types considered, to the lamps from previous studies, which were more of a random sampling. Very few of the RRL2 or RRL1 lamps would have met the selection criteria for RRL3. 


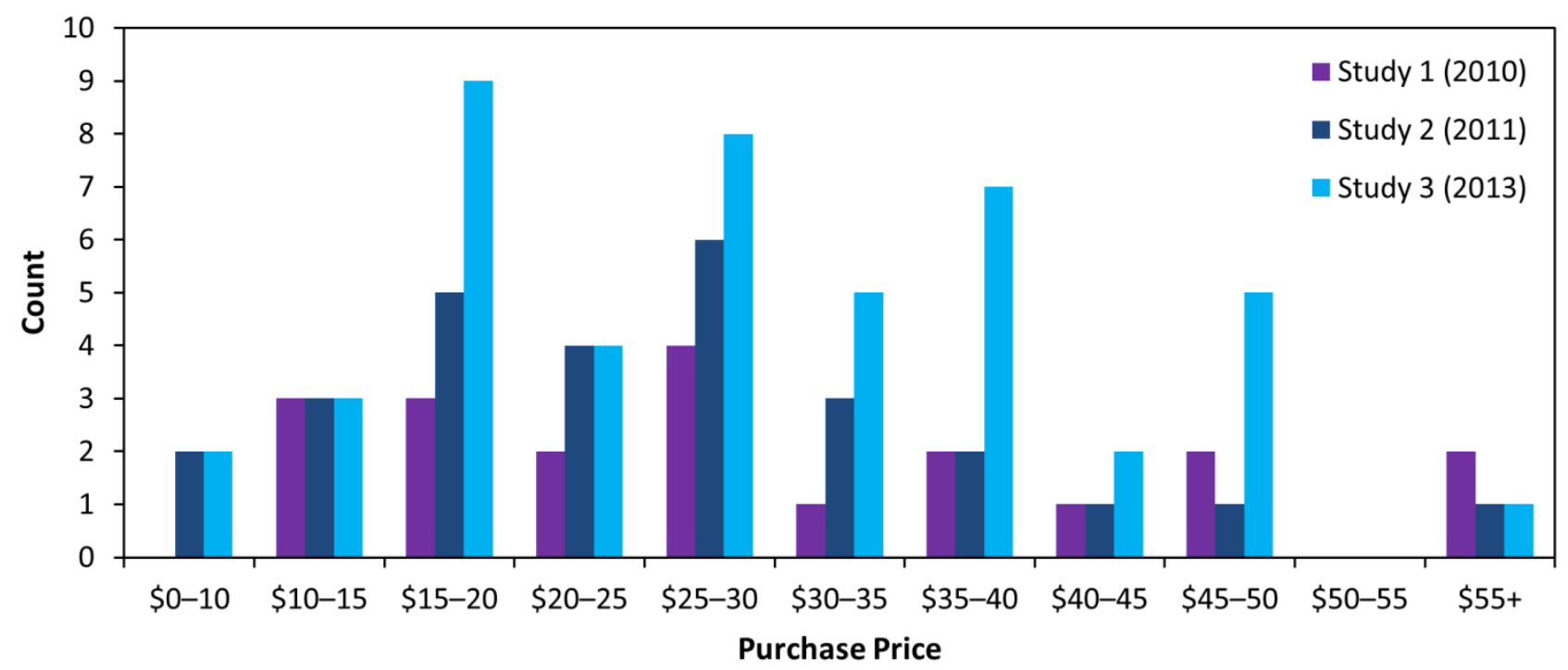

Figure 19. Per lamp cost for each of the CALiPER retail lamp studies. It is important to note that the performance of the lamps in each study was not equivalent.

Table 7. Average price and performance data for five different A lamp product lines as of August 2013. Only three of the five brands had a product in Category 4. Some, but not all, of the product used to derive this data were purchased for RRL3.

\begin{tabular}{lcccc}
\hline & $\begin{array}{c}\text { Category 1 } \\
\text { 450 Lumens } \\
\text { (40 W Incandescent) }\end{array}$ & $\begin{array}{c}\text { Category 2 } \\
800 \text { Lumens } \\
\text { (60 W Incandescent) }\end{array}$ & $\begin{array}{c}\text { Category 3 } \\
1,100 \text { Lumens } \\
\text { (75 W Incandescent) }\end{array}$ & $\begin{array}{c}\text { Category 4 } \\
1,600 \text { Lumens } \\
\text { (100 W Incandescent) }\end{array}$ \\
\hline Mean Price & $\$ 16.18$ & $\$ 19.17$ & $\$ 30.98$ & $\$ 38.31$ \\
Mean \$/klm & $\$ 35.27$ & $\$ 23.17$ & $\$ 27.79$ & $\$ 23.18$ \\
Mean \$/lm/w & $\$ 0.26$ & $\$ 0.25$ & $\$ 0.42$ & $\$ 0.48$ \\
\hline
\end{tabular}

Figures 20 and 21 illustrate price and performance trends for the three retail lamp studies. Given the dissimilarities in the samples, all of these figures should be considered carefully, and conclusions not extrapolated to broader data sets. Figure 20a illustrates lumen output versus price, demonstrating that while average price has remained relatively constant, lumen output has gone up. More specifically, for the same price, the typical product in 2013 has higher lumen output than the typical product in 2010 or 2011 . This is further illustrated in Figure 21 using the mean price per kilolumen $(\$ / \mathrm{klm})$-kilolumen refers to 1,000 lumens. For the combined group of A, PAR, and MR lamps, that metric dropped from a mean of $\$ 214$ in 2010, to a mean of $\$ 85$ in 2011, to a mean of $\$ 49$ in 2013. Figure 20b illustrates efficacy versus price; as with lumen output, the products from RRL3 generally had higher efficacy at any given price point, although the effect was less than for lumen output. As shown in Figure 21, the price per lumen-per-watt dropped from a mean of $\$ 0.78$ in 2010 to $\$ 0.50$ in 2011 to $\$ 0.48$ in 2013.

Another important outcome illustrated in Figures 20 and 21 is that price does not necessarily correlate with higher performance. For both efficacy and lumen output (as well as color quality and power quality, not shown), the higher-priced products performed similarly to the lower-priced products-in many cases, linear trend lines, though with poor correlation coefficients, would indicate a slight decline in performance with higher price. This was apparent when considering all three types of products combined, or each group individually. Although 

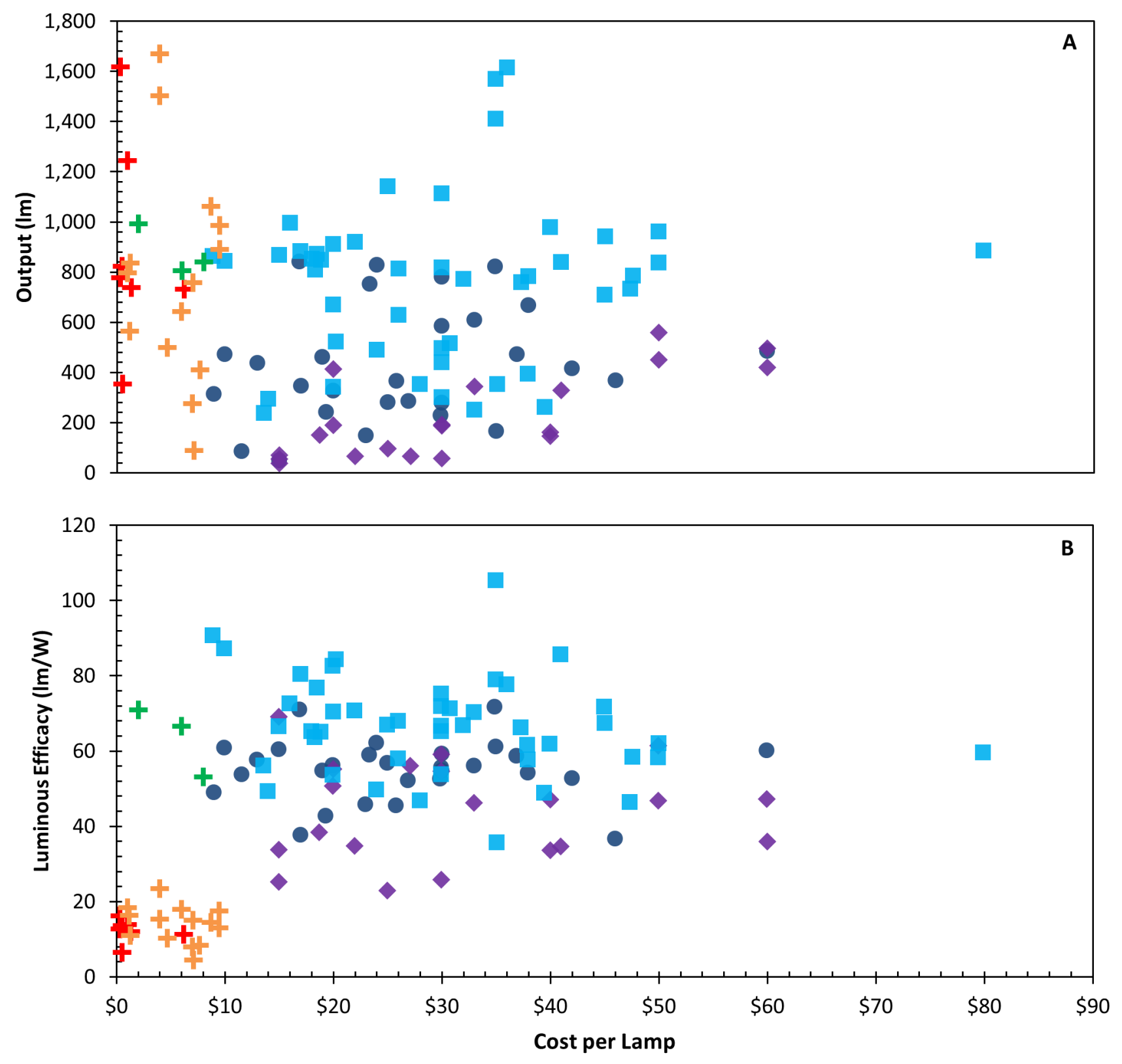

Retail Lamps Study 3 (2013) + Incandescent Benchmarks (2010-2011)

- Retail Lamps Study 2 (2011) + Halogen Benchmarks (2010-2013)

Retail Lamps Study 1 (2010) + CFL Benchmarks (2010-2013)

Figure 20. A. Lumen output versus cost for the lamps purchased for the three CALiPER retail lamp studies. While higher lumen output is not correlated with higher price within any given study-or as a whole-each successive study has demonstrated a drop in the cost per lumen.

B. Efficacy versus cost for each product in the CALiPER retail lamp study series. Differences in price trends for the three studies must be considered cautiously due to the different nature of the selection processes. For RRL3, selection favored higher-output products, which tend to have a higher price per lumen-per-watt (Table 7). 

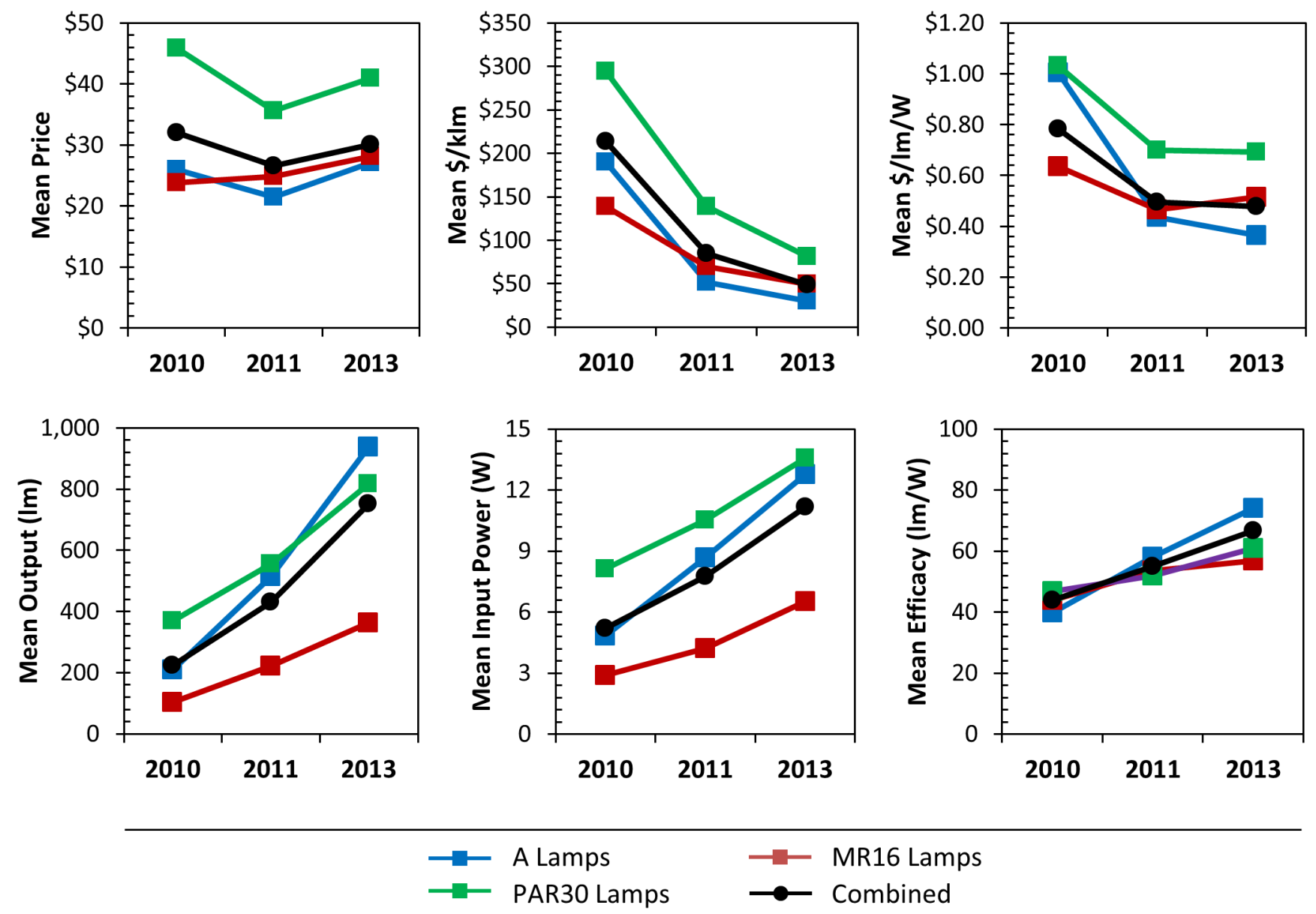

Figure 21. LED price and performance trends seen in the three retail lamp studies.

difficult to confirm empirically, one contributing factor may be differences between products that have been on the market longer (which tend to have higher prices) and new products (which often seem to be introduced at a lower price). In the past year, a number of 800-lumen omnidirectional A lamps have become available at a price of less than $\$ 10$. As shown in Figure 20, this is very close to the price of a typical CFL with similar lumen output, and the efficacy may be $25 \%$ higher or more.

\section{Claims Summary}

Table 8 presents a summary of evaluations related to manufacturer and retailer claims of equivalence and provided data. Each product was evaluated based on eight types of data, using a three-tier system. The data types and criteria are as follows:

\section{Equivalency Claim: Lumen Output (A19) or CBCP (PAR30 or MR16)}

Emitted less than $95 \%$ of the appropriate lumen output ${ }^{19}$ (A19/A21), or emitted less than the allowable value of the ENERGY STAR equivalency tool (PAR30, MR16)

Emitted between $95 \%$ and $100 \%$ of the appropriate lumen output (A lamps)

Exceeded the appropriate lumen output (A lamps) or CBCP (PAR30, MR16)

\footnotetext{
${ }^{19}$ The appropriate lumen output used by CALiPER is $40 \mathrm{~W}=450 \mathrm{Im}, 60 \mathrm{~W}=800 \mathrm{Im}, 75 \mathrm{~W}=1,100 \mathrm{Im}, 100 \mathrm{~W}=1,600 \mathrm{Im}$. These match ENERGY STAR criteria, and are backed up by benchmark tests.
} 


\section{Equivalency Claim: Luminous Intensity Distribution}

Did not have the same distribution as the benchmark products (e.g., semi-directional instead of omnidirectional, directional lamp with beam angle over $100^{\circ}$ ); deviation greater than $50 \%$ at a given vertical angle

Some deviation (greater than $30 \%$ at a given vertical angle) from the benchmark distribution

Closely approximated the distribution of the benchmark product

\section{Equivalency Claim: Color Quality (CRI, CCT, and $\mathrm{D}_{\mathrm{uv}}$ )}

- Had a CRI less than $79, C C T$ above $3500 \mathrm{~K}$, or $\mathrm{D}_{\mathrm{uv}}$ outside ANSI tolerances $( \pm 0.006)$

Had a CRI of 79 or above, a nominal CCT of $2700 \mathrm{~K}$ or $3000 \mathrm{~K}$, and a $\mathrm{D}_{\mathrm{uv}}$ within ANSI tolerances $( \pm 0.006)$

\section{Equivalency Claim: Size}

Exceeded ANSI tolerances for diameter or length by more than $5 \%$.

Met or was within both diameter and length tolerances established by ANSI

5. Manufacturer Data: Lumen Output

Emitted less than $90 \%$ of the listed lumen output

Emitted more than $110 \%$ of the listed lumen output

Emitted between $90 \%$ and $110 \%$ of the listed lumen output

\section{Manufacturer Data: Input Power}

Drew more than $110 \%$ of the listed input power

Drew less than $90 \%$ of the listed input power

Drew between $90 \%$ and $110 \%$ of the listed input power

\section{Manufacturer Data: Beam Angle}

Was not omnidirectional or exceeded ANSI tolerances for listed beam angle

Emitted light in all directions ("Omni") or was within ANSI tolerances for listed beam angle

\section{Manufacturer Data: Color Quality (CRI, CCT)}

- CRI was more than $10 \%$ different from listed value; nominal listed CCT was not accurate

CRI was less than $10 \%$ different from listed value; nominal listed CCT was accurate

In total, the results indicate the accuracy of claims continues to be problematic, with some variation between product types. Overall, $43 \%$ of products made an equivalency claim that was not entirely accurate (red square), and $20 \%$ of products were measured to have different performance than claimed in at least one area (red square). Only $37 \%$ and $59 \%$ of products were completely accurate for their equivalency claim and manufacturer data, respectively. The numbers were slightly better for products listed by LED Lighting Facts or qualified by ENERGY STAR, although some of the products in both groups still received at least one red rating. Importantly, the equivalency considered in this report evaluates only a select number of metrics; others, like flicker and dimming, are more difficult to quantify and even harder to equate across technologies.

Despite the substantial number of products that failed to meet their claims, the numbers are better than they were for the 2011 study, where 52\% of the A19, PAR30, and MR16 lamps that made an equivalency claim failed to meet it, based on lumen output/CBCP alone. At the same time, however, only two lamps from RRL2 (of the relevant product types) emitted less than $90 \%$ of the lumen output claimed by the manufacturer-out of 28 total. However, eight of the RRL2 products emitted more than $110 \%$ of the claimed output.

By far the most problematic metric was meeting the lumen output or $\mathrm{CBCP}$ required of the equivalency claim. Fourteen products failed that evaluation. The next worst category was meeting the manufacturer's claimed 
output, which seven products failed, followed by having an appropriate luminous intensity distribution for the equivalency claim, which five products failed. Importantly, failing to meet manufacturer data was not a prerequisite for not meeting the equivalency claim; in some cases, the tested product performance matched the manufacturer's published data, but the performance is not consistent with the equivalency claim. Of course, there is no legislation to dictate precisely what performance levels must be achieved for a specific equivalency claim, although the performance levels seem to be well known and consistent across various programs.

One final point of interest is discrepancies between manufacturer and retailer data. For a majority of products, the data provided by both sources was in alignment. However, nine products had different values listed by the manufacturer and retailer for lumen output, with a maximum difference of 160 lumens. In most cases, these differences are not substantial enough to warrant serious concern. Likewise, three products had a different input power listed by the retailer compared to the manufacturer's specification sheet. In contrast, all the products had the same nominal CCT listed by both data sources. The origin of any discrepancies is difficult to identify. They could arise from data entry errors-more than one typographical error was noted on retailer webpages -small updates to products without relaying of new data, or simply rounding of numbers.

One interesting question to consider regarding claims is whether they are worse for LED products than conventional lighting technologies, or any other type of product that consumers typically purchase. While CALiPER is unable to evaluate the latter, it is possible to report that just one of the eight benchmark products

Table 8. Summary of claim evaluations. The numbered columns and color-coding correspond to the criteria listed above. Cells shaded gray were not evaluated.

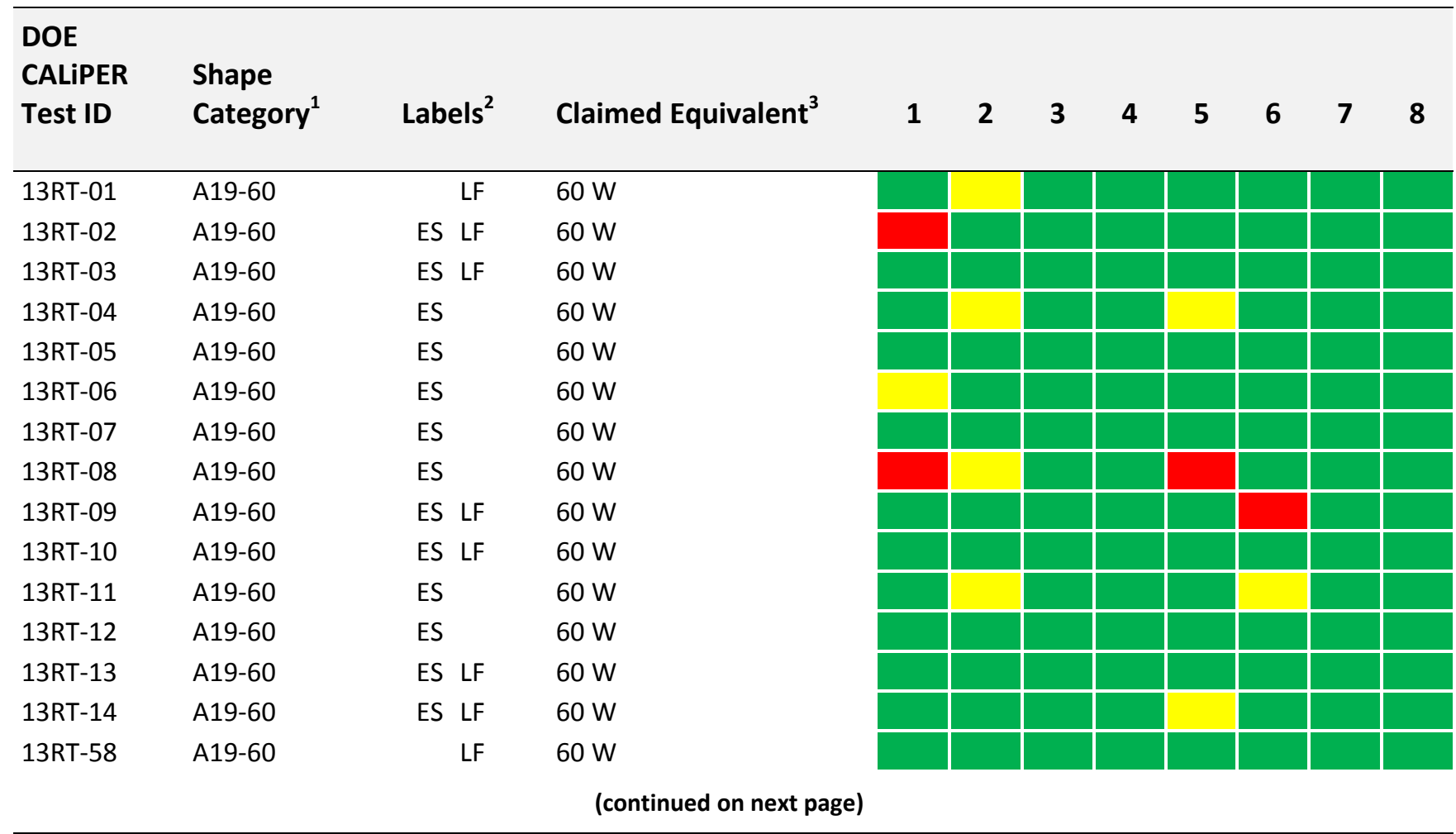

1. Shape category is the grouping used by CALIPER, with the approximate shape and equivalency claim shown in the code. Claims were evaluated using the actual equivalency claim, which varied for a few products.

2. The labels indicate whether a product was ENERGY STAR qualified (ES) or listed by LED Lighting Facts (LF), as identified by CALiPER.

3. The equivalency claim is made by the manufacturer and/or retailer. For products where the two claims did not match, the retailer

claim is shown in parentheses. 
Table 8. (continued)

\begin{tabular}{|c|c|c|c|c|c|c|c|c|c|c|c|c|}
\hline $\begin{array}{l}\text { DOE } \\
\text { CALiPER } \\
\text { Test ID }\end{array}$ & $\begin{array}{l}\text { Shape } \\
\text { Category }^{1}\end{array}$ & Labe & $\mathrm{els}^{2}$ & Claimed Equivalent $^{3}$ & 1 & 2 & 3 & 4 & 5 & 6 & 7 & 8 \\
\hline 13RT-18 & A19-75 & & $\mathrm{LF}$ & $75 \mathrm{~W}$ & & & & & & & & \\
\hline 13RT-19 & A19-75 & & & $75 \mathrm{~W}$ & & & & & & & & \\
\hline 13RT-20 & A19-75 & ES & & $75 \mathrm{~W}$ & & & & & & & & \\
\hline 13RT-23 & A19-75 & & & $75 \mathrm{~W}$ & & & & & & & & \\
\hline 13RT-24 & A19-75 & & & $75 \mathrm{~W}$ & & & & & & & & \\
\hline 13RT-25 & A21-75 & & LF & $75 \mathrm{~W}$ & & & & & & & & \\
\hline 13RT-21 & A21-100 & & LF & $100 \mathrm{~W}(75 \mathrm{~W})$ & & & & & & & & \\
\hline $13 R T-22$ & A19-100 & & & $100 \mathrm{~W}$ & & & & & & & & \\
\hline 13RT-26 & A21-100 & & LF & $100 \mathrm{~W}$ & & & & & & & & \\
\hline $13 R T-27$ & PAR30 & ES & LF & $75 \mathrm{~W}$ & & & & & & & & \\
\hline 13RT-28 & PAR30 & ES & & $75 \mathrm{~W}$ & & & & & & & & \\
\hline $13 R T-29$ & PAR30 & ES & & $75 \mathrm{~W}$ & & & & & & & & \\
\hline $13 R T-30$ & PAR30 & ES & LF & $90 \mathrm{~W}(80 \mathrm{~W})$ & & & & & & & & \\
\hline 13RT-31 & PAR30 & ES & LF & $75 \mathrm{~W}$ & & & & & & & & \\
\hline $13 R T-32$ & PAR30 & ES & LF & $75 \mathrm{~W}(100 \mathrm{~W})$ & & & & & & & & \\
\hline 13RT-33 & PAR30 & ES & & $75 \mathrm{~W}$ & & & & & & & & \\
\hline $13 R T-34$ & PAR30 & & & $60 \mathrm{~W}$ & & & & & & & & \\
\hline 13RT-35 & PAR30 & ES & $\mathrm{LF}$ & $75 \mathrm{~W}$ & & & & & & & & \\
\hline 13RT-36 & MR16-35 & & & $35 \mathrm{~W}$ & & & & & & & & \\
\hline 13RT-37 & MR16-35 & & & $35 \mathrm{~W}$ & & & & & & & & \\
\hline 13RT-38 & MR16-50 ${ }^{4}$ & & $\mathrm{LF}$ & $50 \mathrm{~W}$ & & & & & & & & \\
\hline 13RT-39 & MR16-50 & ES & LF & $50 \mathrm{~W}$ & & & & & & & & \\
\hline $13 R T-40$ & MR16-35 & ES & LF & No Claim & & & & & & & & \\
\hline 13RT-41 & MR16-50 & & LF & $50 \mathrm{~W}$ & & & & & & & & \\
\hline $13 R T-42$ & MR16-35 & & & $35 \mathrm{~W}$ & & & & & & & & \\
\hline 13RT-43 & MR16-50 ${ }^{4}$ & & & $50 \mathrm{~W}$ & & & & & & & & \\
\hline 13RT-44 & MR16-50 & ES & & $50 \mathrm{~W}$ & & & & & & & & \\
\hline 13RT-45 & MR16-50 ${ }^{4}$ & & & No Claim & & & & & & & & \\
\hline 13RT-46 & MR16-35 & & & No Claim & & & & & & & & \\
\hline $13 R T-47$ & MR16-35 & & $\mathrm{LF}$ & $35 \mathrm{~W}$ & & & & & & & & \\
\hline 13RT-48 & MR16-50 & & & No Claim (40 W) & & & & & & & & \\
\hline
\end{tabular}

1. Shape category is the grouping used by CALIPER, with the approximate shape and equivalency claim shown in the code. Claims were evaluated using the actual equivalency claim, which varied for a few products.

2. The labels indicated whether a product was ENERGY STAR qualified (ES) or listed by LED Lighting Facts (LF).

3. The equivalency claim is that made by the manufacturer and retailer. For products where the two claims didn't match, the retailer claim is shown in parentheses.

tested for RRL3 had lumen output that was more than $10 \%$ different from the listed value. On average, product BK13RT-58 emitted $89.6 \%$ of the lumen output listed by the manufacturer. That same product, as well as BK13RT-51, had a slightly lower efficacy than claimed. Although it is a much smaller sample, this data indicates that conventional products - the performance of which has been fine-tuned over many years-generally have more accurate reported performance. 


\section{Conclusions}

The retail LED lamp market has been continually evolving, but with multiple, high-quality, sub-\$10 products now on the market, it has the potential to rapidly pick up pace. When the RRL2 study was completed in 2011, it seemed like the market had jumped leaps and bounds since the RRL1 study completed a year earlier. Even though that was true, there was still much room for improvement. While not all metrics will capture the tremendous shift in the market (e.g., $\$ / \mathrm{lm} / \mathrm{W}$ ), the availability of vastly superior products for RRL3 in 2013 is undeniable. For example, whereas 800 -lumen A lamps were a rarity two years ago, they are now commonplace, as are PAR30 lamps over 800 lumens. In fact, a substantial portion of the products tested for this report exceeded the lumen output and efficacy performance of the very best products from 2011. Such dramatic gains in performance are not universal, however. There are still poor-performing products on the market-even ones that make lofty claims - and the accuracy of equivalency claims and data remains a problem.

The 46 products tested for this report were chosen to address several specific hypotheses. A brief summary of those hypotheses and the resulting outcomes are as follows:

- Compared to the previous study, new products are available that push the boundaries of lumen output equivalency.

The progression of LED products to higher lumen output levels is strongly confirmed by the data collected for this report. For all three product types considered-A19, PAR30, and MR16-multiple products were available that exceeded the maximum lumen output and efficacy from the previous retail lamp study in 2011.

- Manufacturer claims and retailer claims for photometric performance are more likely to be met now than they were in RRL2 or RRL1.

Almost every product included in this study made an equivalency claim based on the performance of an incandescent or halogen lamp-many of which will be disappearing from store shelves soon. While those claims were somewhat more accurate than two years ago, they are still a significant concern for LED lamps sold in the retail market. Overall, $43 \%$ of the products tested for RRL3 made an equivalency claim that was not entirely accurate, and $20 \%$ of products were measured to have different performance than claimed in at least one area. Only $37 \%$ and $59 \%$ of products were completely accurate for their equivalency claim and manufacturer data, respectively.

- Performance has improved since RRL2.

Using any available metric, lamps purchased for RRL3 were vastly superior to those purchased for RRL2. However, in large part this was due to the selection process. Nonetheless, many of the RRL3 products exceeded even the best-performing products that were tested for RRL2.

- Price and price per unit performance has decreased since the last retail lamp study. Overall, the price per product was about the same as it was in 2011, but performance was very different. The price per lumen continued to decline, although the percentage change between 2013 and 2011 was less than it was between 2011 and 2010. The price per lumen per watt changed very little. Now that performance according to the basic metrics is equivalent for a wide range of products, it is possible that price will drop faster in the future. 
- There have been physical changes to the lamp designs, with new optical systems resulting in different luminous intensity distributions.

The widespread availability of A lamps with omnidirectional distributions speaks directly to the evolving LED market. The diversity of design for those products, however, illustrates the many approaches that are being explored and the lack of a single "best" solution. Innovation is continuing, and the lamps on store shelves in a few years may look substantially different from the ones purchased for this report.

Despite all the progress that has been made in the past two years, LED lamps available through retail channels continue to exhibit a range of quality. While in some markets this can be beneficial, for today's LED products, price and performance are not correlated. Thus, consumers, contractors, and other specifiers must be more educated than ever before in order to purchase products that meet their expectations, which are typically based on the performance of conventional products. Further, it is insufficient to create "best" lists, because there are often tradeoffs-like color rendering for efficacy - that make different products better for different applications, or different products more or less acceptable to different users. Despite these issues, the series of retail lamp studies conducted by CALIPER continues to indicate improving performance, and more "bang for the buck." A combination of improving performance and knowledgeable users who are able to match products with a given application will help lead to widespread adoption of LED technology. 


\author{
Beam Angle \\ Degrees $\left({ }^{\circ}\right)$

\section{Center Beam \\ Candlepower (CBCP) \\ Candela (cd) \\ Correlated Color \\ Temperature (CCT) \\ Kelvin (K)}

Color Quality Scale (CQS)

\section{Color Rendering Index (CRI or $\mathrm{R}_{\mathrm{a}}$ )}

$D_{\text {uv }}$

\author{
Field Angle \\ Degrees $\left({ }^{\circ}\right)$
}

\section{Input Power}

Watts (W)

\section{Luminous Efficacy Lumens per watt (Im/W)

Luminous Intensity
Distribution
Candela (cd)
Output
Lumens (Im)

The angle between the two directions for which the intensity is $50 \%$ of the maximum intensity (ANSI/IES RP-16-10) or center beam intensity (ANSI C78.3792006), as measured in a plane through the beam axis. For example, if the maximum intensity is $1000 \mathrm{~cd}$, the angle at which the intensity is $500 \mathrm{~cd}$ is half of the beam angle. If $500 \mathrm{~cd}$ occurs at $20^{\circ}$ from center beam, then the beam angle is $40^{\circ}$.

The luminous intensity at the central axis of the beam, which typically corresponds to a vertical angle of $0^{\circ}$ (called nadir for lamps oriented downward). Although candlepower is a deprecated term, it is still widely used in this context.

The absolute temperature of a blackbody radiator having a chromaticity that most nearly resembles that of the light source. СCT is used to describe the color appearance of the emitted light.

CQS was developed by NIST to address methodological concerns with CRI and expand its capabilities. The system includes metrics for color fidelity $\left(\mathrm{Q}_{\mathrm{f}}\right)$, color gamut $\left(Q_{g}\right)$, and overall color quality $\left(Q_{a}\right)$. To date, the metric has not been officially obtained by any standards organization. More information can be found at: http://www.nist.gov/pml/div685/grp03/vision_color.cfm

A measure of color fidelity that characterizes the general similarity in color appearance of objects under a given source relative to a reference source of the same CCT. The maximum possible value is 100 , with higher scores indicating less difference in chromaticity for a sample of eight color samples illuminated with the test and reference source. See also: Special Color Rendering Index $R_{g}$.

The distance from the Planckian locus on the CIE 1960 UCS chromaticity diagram (also known as $u^{\prime}, 2 / 3 v^{\prime}$ ). A positive value indicates the measured chromaticity is above the locus (appearing slightly green) and a negative value indicates the measured chromaticity is below the locus (appearing slightly pink). The American National Standards Institute provides limits for $D_{u v}$ for nominally white light.

The angle between the two directions for which the intensity is $10 \%$ of the maximum intensity (ANSI/IES RP-16-10) or center beam intensity (ANSI C78.3792006), as measured in a plane through the beam axis. For example, if the CBCP is $1000 \mathrm{~cd}$, the angle at which the intensity is $100 \mathrm{~cd}$ is half of the field angle. If 100 cd occurs at $32^{\circ}$ from center beam, then the field angle is $64^{\circ}$.

The power required to operate a device (e.g., a lamp or a luminaire), including any auxiliary electronic components (e.g., ballast or driver).

The quotient of the total luminous flux emitted and the total input power.

The directionality of radiant energy emitted by a source, which may be shown using one of several techniques. It is most often presented as a polar plot of the candelas emitted in a vertical plane through the center of the lamp or luminaire.

The amount of light emitted by a lamp or luminaire. The radiant energy is weighted with the photopic luminous efficiency function, $V(\lambda)$. 
Power Factor

Special Color

Rendering Index $\mathbf{R}_{\mathbf{9}}$

Spectral Power

Distribution (SPD)
The quotient of real power (watts) flowing to the load (e.g., lamp or fixture) and the apparent power (volt-amperes) in the circuit. Power factor is expressed as a number between 0 and 1, with higher values being more desirable.

A measure of color fidelity that characterizes the similarity in color appearance of deep red objects under a given source relative to a reference source of the same CCT. The maximum possible value is 100 , with higher scores indicating less difference in chromaticity for the color sample illuminated with the test and reference source. $R_{9}$ and $R_{a}$ (CRI) are part of the same CIE Test-Color Method, but the $R_{9}$ color sample is not included in calculation of $R_{a}$. $R_{9}$ values should not be compared to $R_{a}(C R I)$ values. As a shorthand approximation, an $R_{9}$ less than zero is poor, an $R_{9}$ greater than zero is good, an $R_{9}$ greater than 50 is very good, and an $\mathrm{R}_{9}$ greater than 75 is excellent.

The radiant energy emitted by a source over the range of visible wavelengths (approximately $380 \mathrm{~nm}$ to $780 \mathrm{~nm}$ ). 
Table B1. Brand and model information for the 46 LED products tested for this report.

\begin{tabular}{|c|c|c|}
\hline $\begin{array}{l}\text { DOE CALIPER } \\
\text { Test ID }\end{array}$ & Brand & Model \\
\hline 13RT-01 & $3 \mathrm{M}$ & RRA19B3 \\
\hline 13RT-02 & Bulbrite & LED12A19/0/30K/D \\
\hline 13RT-03 & Cree & BA19-08027OMF-12DE26-1U100 \\
\hline 13RT-04 & EcoSmart & ECS A19 WW 60WE 120 \\
\hline 13RT-05 & Feit Electric & A19/OM800/LED \\
\hline 13RT-06 & GE Lighting & LED13DA19/830, 65386 \\
\hline 13RT-07 & Insignia & NS-LED60FB \\
\hline 13RT-08 & LEDnovation & LEDH-A19-60-1-27D-IO-E \\
\hline 13RT-09 & MaxLite & SKBO10DLED30 \\
\hline $13 R T-10$ & Philips Lighting & BC11A19/AMB/2700 DIM120V \\
\hline 13RT-11 & Great Value & GVRLAS11W27KND \\
\hline 13RT-12 & Satco & LED/9.8W/2700K/120V \\
\hline 13RT-13 & Switch & Switch 60/ A22141FA1-R \\
\hline 13RT-14 & OSRAM Sylvania & LED12A19/DIM/O/827/HVP/ \\
\hline $13 R T-58$ & Cree & BA19-08027OMN-12DE26-1U100 \\
\hline 13RT-18 & OSRAM Sylvania & LED14A19/DIM/O/827/ \\
\hline 13RT-19 & EcoSmart & ECS A19 75WE W27 120 \\
\hline 13RT-20 & Feit Electric & A19/OM1100/LED \\
\hline 13RT-23 & Kobi Electric & LED-AD-15W1100-27 \\
\hline 13RT-24 & Aluratek & ALB10W \\
\hline 13RT-25 & Philips Lighting & BC15A21/AMB/2700 DIM WHT 120V \\
\hline 13RT-21 & OSRAM Sylvania & LED20A21/DIM/O/827/ \\
\hline 13RT-22 & Premiertek & LED-7W3200 \\
\hline $13 R T-26$ & Philips Lighting & BC19A21/AMB/2700 DIM WHT 120V \\
\hline 13RT-27 & OSRAM Sylvania & LED17PAR30LN/DIM/P/930/NFL25/HVP \\
\hline $13 R T-28$ & Philips Lighting & 13PAR30L/AMB/F25DIM 3000 120V \\
\hline 13RT-29 & EcoSmart & ECS 30 WW FL 75WE 120 \\
\hline $13 R T-30$ & GE Lighting & LED12DP30S827/35 \\
\hline 13RT-31 & Feit Electric & 15PAR30L/LEDG5 \\
\hline 13RT-32 & $\mathrm{TCP}$ & LED14E26P3030KFL \\
\hline $13 R T-33$ & Bulbrite Industries & LED15PAR30WW/FL/D \\
\hline 13RT-34 & Viribright & 95-10EUS \\
\hline 13RT-35 & Toshiba & LDRB1630ME6USDL \\
\hline 13RT-36 & Utilitech & LEXNDM/LED \\
\hline 13RT-37 & Array Lighting & AACMMR163060 \\
\hline $13 R T-38$ & Philips Lighting & BC6GU10/AMB/F25 3000 DIM 120V \\
\hline 13RT-39 & GE Lighting & LED7XDMR16830/25 \\
\hline $13 R T-40$ & Philips Lighting & 10MR16/END/F24 2700 DIM \\
\hline 13RT-41 & EcoSmart & ECS 16 WW V2 NFL \\
\hline 13RT-42 & Soraa & MR16-36-B01-12-930-36 \\
\hline 13RT-43 & HitLights & HL-LEDGU10WW6WCR \\
\hline $13 R T-44$ & Verbatim & M16ES-L500-C30-B30 \\
\hline $13 R T-45$ & Encore & DP-ESL3*2GU10A4 \\
\hline $13 R T-46$ & Sunlite Electric & MR16/4LED/6.5W/GU5.3/WW/CD1 \\
\hline $13 R T-47$ & Eti Solid State Lighting & 530192 \\
\hline $13 R T-48$ & Light Efficient Design & LED5231 \\
\hline
\end{tabular}


Table C1. Data for A, PAR, and MR lamps tested for RRL1.

\begin{tabular}{|c|c|c|c|c|c|c|c|c|c|}
\hline $\begin{array}{l}\text { DOE } \\
\text { CALIPER } \\
\text { Test ID }\end{array}$ & Shape & $\begin{array}{c}\text { Initial } \\
\text { Output } \\
\text { (Im) }\end{array}$ & $\begin{array}{l}\text { Total } \\
\text { Input } \\
\text { Power } \\
\text { (W) }\end{array}$ & $\begin{array}{l}\text { Efficacy } \\
(\mathrm{Im} / \mathrm{W})\end{array}$ & $\begin{array}{l}\text { Voltage } \\
\text { (V) }\end{array}$ & $\begin{array}{l}\text { Power } \\
\text { Factor }\end{array}$ & CRI & $\begin{array}{l}\mathrm{CCT} \\
(\mathrm{K})\end{array}$ & $D_{u v}$ \\
\hline 10RT-1 & A19 & 160 & 4.8 & 34 & 120 & 0.56 & 79 & 3184 & 0.0040 \\
\hline 10RT-3 & A19 & 343 & 7.4 & 46 & 120 & 0.94 & 81 & 3044 & -0.0019 \\
\hline 10RT-4 & A19 & 65 & 1.9 & 35 & 120 & 0.46 & 81 & 3011 & 0.0032 \\
\hline 10RT-5 & A19 & 412 & 8.1 & 51 & 120 & 0.94 & 86 & 3081 & 0.0007 \\
\hline 10RT-34 & A19 & 69 & 2.0 & 34 & 120 & 0.55 & 81 & 2970 & -0.0019 \\
\hline 10RT-25 & PAR30 & 418 & 11.6 & 36 & 120 & 0.98 & 56 & 3387 & 0.0039 \\
\hline 10RT-26 & PAR30 & 496 & 10.5 & 47 & 120 & 0.99 & 80 & 3060 & -0.0029 \\
\hline 10RT-28 & PAR30 & 145 & 3.1 & 47 & 120 & 0.54 & 82 & 8107 & 0.0020 \\
\hline 10RT-29 & PAR30 & 189 & 3.4 & 55 & 120 & 0.51 & 69 & 5601 & -0.0004 \\
\hline 10RT-30 & PAR30 & 450 & 9.6 & 47 & 120 & 0.87 & 85 & 3093 & -0.0026 \\
\hline 10RT-31 & PAR30 & 329 & 9.5 & 35 & 120 & 0.95 & 82 & 2882 & -0.0045 \\
\hline 10RT-32 & PAR30 & 559 & 9.1 & 61 & 120 & 0.85 & 91 & 2701 & -0.0013 \\
\hline 10RT-10 & MR16 & 56 & 1.0 & 59 & 120 & 0.35 & 63 & 2832 & 0.0012 \\
\hline 10RT-12 & MR16 & 54 & 0.8 & 69 & 120 & 0.29 & 69 & 6143 & 0.0059 \\
\hline 10RT-13 & MR16 & 95 & 4.1 & 23 & 120 & 0.93 & 82 & 3208 & -0.0073 \\
\hline 10RT-18 & MR16 & 64 & 1.1 & 56 & 120 & 0.60 & 62 & 2905 & 0.0037 \\
\hline 10RT-20 & MR16 & 149 & 3.9 & 38 & 120 & 0.93 & 75 & 4477 & 0.0017 \\
\hline 10RT-11 & MR16 & 36 & 1.4 & 25 & 12 & 0.94 & 78 & 3879 & -0.0065 \\
\hline 10RT-14 & MR16 & 191 & 3.5 & 55 & 12 & 0.66 & 87 & 4049 & -0.0040 \\
\hline 10RT-15 & MR16 & 187 & 7.3 & 26 & 12 & 0.96 & 82 & 2836 & 0.0020 \\
\hline
\end{tabular}


Table C2. Data for A, PAR, and MR lamps tested for RRL2.

\begin{tabular}{|c|c|c|c|c|c|c|c|c|c|}
\hline $\begin{array}{l}\text { DOE } \\
\text { CALiPER } \\
\text { Test ID }\end{array}$ & Shape & $\begin{array}{c}\text { Initial } \\
\text { Output } \\
\text { (Im) }\end{array}$ & $\begin{array}{l}\text { Total } \\
\text { Input } \\
\text { Power } \\
\text { (W) }\end{array}$ & $\begin{array}{l}\text { Efficacy } \\
(\mathrm{Im} / \mathrm{W})\end{array}$ & $\begin{array}{l}\text { Voltage } \\
\text { (V) }\end{array}$ & $\begin{array}{l}\text { Power } \\
\text { Factor }\end{array}$ & CRI & $\begin{array}{l}\mathrm{CCT} \\
(\mathrm{K})\end{array}$ & $D_{u v}$ \\
\hline 11RT-43 & A19 & 460 & 8.4 & 55 & 120 & 0.74 & 87 & 2958 & -0.0020 \\
\hline 11RT-46 & A19 & 752 & 12.8 & 59 & 120 & 0.97 & 80 & 2991 & -0.0060 \\
\hline 11RT-47 & A19 & 471 & 7.7 & 61 & 120 & 0.77 & 82 & 3054 & -0.0010 \\
\hline 11RT-49 & A19 & 827 & 13.3 & 62 & 120 & 0.99 & 86 & 3300 & -0.0040 \\
\hline 11RT-57 & A19 & 437 & 7.6 & 58 & 120 & 0.68 & 80 & 3020 & -0.0010 \\
\hline 11RT-61 & A19 & 472 & 8.0 & 59 & 120 & 0.99 & 82 & 3060 & -0.0020 \\
\hline 11RT-62 & A19 & 841 & 11.9 & 71 & 120 & 0.87 & 83 & 2730 & -0.0010 \\
\hline 11RT-64 & A19 & 84 & 1.6 & 54 & 120 & 0.34 & 73 & 3173 & -0.0070 \\
\hline 11RT-72 & A19 & 313 & 6.4 & 49 & 120 & 0.70 & 76 & 4863 & 0.0049 \\
\hline 11RT-74 & A19 & 414 & 7.8 & 53 & 120 & 0.96 & 86 & 3017 & 0.0012 \\
\hline 11RT-77 & A19 & 585 & 9.9 & 59 & 120 & 0.88 & 80 & 3030 & 0.0004 \\
\hline $11 R T-42$ & PAR30 & 365 & 8.0 & 46 & 120 & 0.49 & 67 & 3225 & 0.0061 \\
\hline 11RT-45 & PAR30 & 608 & 10.9 & 56 & 120 & 0.81 & 81 & 3073 & -0.0032 \\
\hline $11 R T-48$ & PAR30 & 780 & 14.2 & 55 & 120 & 0.72 & 86 & 3046 & -0.0043 \\
\hline 11RT-65 & PAR30 & 820 & 11.5 & 72 & 120 & 0.98 & 80 & 3078 & -0.0008 \\
\hline 11RT-68 & PAR30 & 667 & 12.3 & 54 & 120 & 0.82 & 85 & 3037 & -0.0018 \\
\hline 11RT-69 & PAR30 & 485 & 8.1 & 60 & 120 & 0.93 & 86 & 2994 & 0.0009 \\
\hline 11RT-73 & PAR30 & 346 & 9.2 & 38 & 120 & 0.75 & 85 & 2624 & -0.0011 \\
\hline 11RT-76 & PAR30 & 368 & 10.1 & 37 & 120 & 0.95 & 82 & 2984 & -0.0041 \\
\hline $11 R T-40$ & MR16 & 241 & 5.6 & 43 & 120 & 0.63 & 73 & 6085 & 0.0037 \\
\hline 11RT-51 & MR16 & 327 & 5.8 & 56 & 120 & 0.81 & 85 & 2983 & -0.0030 \\
\hline 11RT-53 & MR16 & 147 & 3.2 & 46 & 120 & 0.54 & 83 & 3044 & -0.0041 \\
\hline 11RT-55 & MR16 & 277 & 5.0 & 56 & 120 & 0.76 & 85 & 2982 & -0.0028 \\
\hline 11RT-59 & MR16 & 281 & 5.0 & 57 & 120 & 0.61 & 82 & 3010 & -0.0050 \\
\hline 11RT-63 & MR16 & 228 & 4.3 & 53 & 120 & 0.54 & 82 & 3040 & -0.0033 \\
\hline $11 R T-70$ & MR16 & 165 & 2.7 & 61 & 120 & 0.93 & 86 & 2990 & 0.0014 \\
\hline 11RT-71 & MR16 & 284 & 5.4 & 52 & 120 & 0.63 & 88 & 5492 & 0.0006 \\
\hline 11RT-75 & MR16 & 48 & 0.8 & 60 & 120 & 0.29 & 73 & 6018 & 0.0066 \\
\hline
\end{tabular}


Table D1. CALiPER test data for conventional products used as benchmarks in this report. All data was obtained using the same procedures as were used for the LED products.

\begin{tabular}{|c|c|c|c|c|c|c|c|c|c|c|c|}
\hline $\begin{array}{l}\text { DOE } \\
\text { CALiPER } \\
\text { Test ID }\end{array}$ & $\begin{array}{l}\text { Shape } \\
\text { Type }\end{array}$ & $\begin{array}{l}\text { Source } \\
\text { Type }\end{array}$ & $\begin{array}{c}\text { Initial } \\
\text { Output } \\
\text { (Im) }\end{array}$ & $\begin{array}{l}\text { Total } \\
\text { Input } \\
\text { Power } \\
\text { (W) }\end{array}$ & $\begin{array}{l}\text { Efficacy } \\
(\mathrm{Im} / \mathrm{W})\end{array}$ & $\begin{array}{l}\text { Voltage } \\
\text { (V) }\end{array}$ & $\begin{array}{l}\text { Power } \\
\text { Factor }\end{array}$ & CRI & $\begin{array}{l}\text { CCT } \\
(\mathrm{K})\end{array}$ & $\begin{array}{l}\text { CBCP } \\
\text { (cd) }\end{array}$ & $\begin{array}{l}\text { Beam } \\
\text { Angle } \\
\text { (deg) }\end{array}$ \\
\hline $08-04$ & A19 & Incan. & 353 & 54.6 & 7 & $120^{1}$ & 1.00 & 99 & 2491 & - & - \\
\hline $08-49$ & A19 & Incan. & 739 & 61.0 & 12 & 120 & 1.00 & 100 & 2703 & - & - \\
\hline $10-31$ & A19 & Incan. & 823 & 60.6 & 14 & 120 & 1.00 & 100 & 2771 & - & - \\
\hline $11-09$ & A19 & Incan. & 1,618 & 100.0 & 16 & 120 & 1.00 & 100 & 2819 & - & - \\
\hline $11-11$ & A19 & Incan. & 1,694 & 101.0 & 17 & 120 & 1.00 & 100 & 2854 & - & - \\
\hline $11-12$ & A19 & Incan. & 1,322 & 99.0 & 13 & 120 & 1.00 & 100 & 2871 & - & - \\
\hline $11-25$ & A19 & Incan. & 1,245 & 89.8 & 14 & 120 & 1.00 & 100 & 2764 & - & - \\
\hline $13 R T-16$ & A19 & Incan. & 808 & 61.2 & 13 & 120 & 1.00 & 99 & 2723 & - & - \\
\hline $11-24$ & A19 & Halogen & 1,671 & 71.0 & 24 & 120 & 1.00 & 99 & 2863 & - & - \\
\hline $11-10$ & A19 & Halogen & 1,550 & 73.0 & 21 & 120 & 1.00 & 100 & 3020 & - & - \\
\hline $11-13$ & A19 & Halogen & 837 & 75.0 & 11 & 120 & 1.00 & 84 & 2805 & - & - \\
\hline $11-14$ & A19 & Halogen & 1,433 & 79.0 & 18 & 120 & 1.00 & 99 & 2974 & - & - \\
\hline $11-15$ & A19 & Halogen & 1,503 & 98.0 & 15 & 120 & 1.00 & 100 & 2858 & - & - \\
\hline 13RT-15 & A19 & Halogen & 796 & 43.4 & 18 & 120 & 1.00 & 99 & 2916 & - & - \\
\hline $08-27$ & A19 & CFL & 806 & 12.1 & 67 & 120 & 0.56 & 82 & 2703 & - & - \\
\hline 13RT-17 & A19 & CFL & 993 & 14.0 & 71 & 120 & 0.59 & 83 & 2689 & - & - \\
\hline $08-13$ & R30 & Incan. & 732 & 65.0 & 11 & 120 & 1.00 & 99 & 2681 & 431 & 74 \\
\hline 13RT-55 & PAR30 & Halogen & 891 & 51.0 & 17 & 120 & 1.00 & 99 & 2767 & 4,538 & 23 \\
\hline 13RT-56 & PAR30 & Halogen & 986 & 75.5 & 13 & 120 & 1.00 & 100 & 2835 & 2,235 & 35 \\
\hline 13RT-57 & PAR30 & Halogen & 1,061 & 73.3 & 14 & 120 & 1.00 & 100 & 2892 & 1,377 & 48 \\
\hline 08-06 & R30 & CFL & 841 & 15.8 & 53 & 120 & 0.55 & 82 & 2740 & 236 & 110 \\
\hline $11-90$ & MR16 & Halogen & 88 & 19.8 & 5 & 120 & 1.00 & 99 & 2514 & 140 & 37 \\
\hline $11-91$ & MR16 & Halogen & 410 & 49.3 & 8 & 120 & 1.00 & 100 & 2804 & 759 & 33 \\
\hline $11-92$ & MR16 & Halogen & 275 & 34.9 & 8 & 120 & 1.00 & 99 & 2693 & 675 & 25 \\
\hline 13RT-50 & MR16 & Halogen & 564 & 34.7 & 16 & 12 & 1.00 & 100 & 2917 & 1,432 & 27 \\
\hline 13RT-51 & MR16 & Halogen & 644 & 35.8 & 18 & 12 & 1.00 & 100 & 2982 & 1,592 & 32 \\
\hline $13 R T-53$ & MR16 & Halogen & 757 & 50.1 & 15 & 12 & 1.00 & 97 & 3079 & 8,909 & 13 \\
\hline $13 R T-54$ & MR16 & Halogen & 499 & 48.4 & 10 & 120 & 1.00 & 99 & 2776 & 1,186 & 25 \\
\hline
\end{tabular}

1. This lamp was rated for $130 \mathrm{~V}$, but tested at $120 \mathrm{~V}$. 


\section{DOE SSL Commercially Available LED Product Evaluation and Reporting Program NO COMMERCIAL USE POLICY}

The U.S. Department of Energy (DOE) is a federal agency working in the public interest. Published information from the DOE SSL CALiPER program, including test reports, technical information, and summaries, is intended solely for the benefit of the public, in order to help buyers, specifiers of new SSL products, testing laboratories, energy experts, energy program managers, regulators, and others make informed choices and decisions about SSL products and related technologies.

Such information may not be used in advertising, to promote a company's product or service, or to characterize a competitor's product or service. This policy precludes any commercial use of any DOE SSL CALiPER Program published information in any form without DOE's express written permission. 
